Arqueología y Sociedad,

№ 20, 2009

\title{
SOBRE LAS OCUPACIONES PREHISPÁNICAS \\ EN LA CUENCA BAJA DEL RÍO NEGROMAYO \\ (LUCANAS-AYACUCHO): UNA APROXIMACIÓN \\ DESDE EL SITIO ARQUEOLÓGICO DE CANICHI
}

Jorge Cámara Guerrero*

\begin{abstract}
Resumen
El presente trabajo es un reporte elaborado a partir de un reconocimiento superficial en Canichi, un asentamiento arqueológico localizado en la margen izquierda del río Negromayo, provincia de Lucanas, región Ayacucho. Tomando como base las evidencias arqueológicas y utilizando referencias etnohistóricas de manera complementaria, se discuten tanto la ubicación cronológica como la naturaleza de las ocupaciones durante los períodos tardíos, enfatizando el rol que habría desempeñado Canichi a lo largo de la cuenca baja durante el período Intermedio Tardío y los cambios o continuidades en la organización social de los pobladores locales durante el proceso de conquista y consolidación del Estado Inka en la región.
\end{abstract}

\section{Palabras Clave}

Conquista Inka, Cuenca del Negromayo, Etnohistoria, período Intermedio Tardío, Patrón de asentamiento.

\begin{abstract}
This report has been made since a superficial recognition at Canichi, an archeological settlement located on the left bank of Negromayo River, Lucanas Province, Ayacucho Department. Based on archaeological evidences and with the use of ethnohistorical references, in a complementary way, both chronological position and the nature of belated period activities will be discussed in the following report, emphasizing the role that Canichi could have played along the lower basin throughout the Late Intermediate Period and changes and continuities in the social organization of local residents during the process of conquest and consolidation of the Inka State in the region.
\end{abstract}

Keywords

Inka Conquest, The Negromayo basin, Ethnohistory, Late Intermediate Period, Settlement Pattern.

* Estudiante de la Escuela Académico Profesional de Arqueología. UNMSM.

Correo electrónico: jrcg04@yahoo.es 
A la memoria de Luis A. Flores Pinedo entrañable amigo y colega del quehacer arqueológico

\section{INTRODUCCIÓN}

Desde finales del año 2006 hemos venido desarrollando trabajos de reconocimiento arqueológico en la cuenca del río Negromayo, ubicada en la provincia de Lucanas, región de Ayacucho, con el objetivo de encontrar nuevos derroteros de investigación sobre las ocupaciones tardías (Intermedio Tardío y Horizonte Tardío) en una zona escasamente estudiada de manera sistemática. De esta manera, nuestra investigación intenta explicar desde una perspectiva regional y diacrónica el desarrollo histórico social de los distintos grupos poblacionales establecidos en la cuenca del río Negromayo durante los últimos períodos de ocupación prehispánica.

Como parte de dicha investigación, los datos presentados en este reporte están relacionados específicamente a un asentamiento arqueológico de un total de siete yacimientos registrados hasta el momento en la cuenca baja del Negromayo por nuestro equipo de investigación (fig. 1). Sin embargo somos concientes de las limitaciones que tendremos al momento de intentar explicar ciertos fenómenos sociales por trabajar básicamente con material de superficie, lo cual advierte desde ahora la necesidad de realizar estudios sistemáticos con secuencias estratigráficas y fechados radiocarbónicos para un mejor entendimiento sobre el desarrollo de los grupos poblacionales establecidos en la cuenca del Negromayo durante estos períodos y sus respectivas comparaciones con otras regiones de los Andes Centrales.

En vista que nuestra investigación aborda la problemática de los períodos tardíos en la sierra andina, es necesario aclarar que la mayoría de investigaciones realizadas en otras regiones abordan el problema desde el punto de vista etnohistórico, lo cual ha generado un problema al momento de caracterizar grupos sociales, diferenciándolos sólo a partir de documentación colonial temprana, generalizando aspectos de la vida social que el registro arqueológico muchas veces contradice.

Hecha la aclaración del problema, nuestra investigación parte esencialmente de evidencia arqueológica concreta, utilizando la fuente etnohistórica como dato complementario al registro arqueológico.

\section{La CUENCA baja Del Negromayo: CARACTERÍs- TICAS GEOGRÁFICAS Y MEDIOAMBIENTALES}

La cuenca del Negromayo se encuentra en la sierra centro-sur peruana y está irrigada por las aguas del río Negromayo (fig. 2), el cual se origina a partir de la unión de dos riachuelos: el Hatun Huamani y el Visca o Chuspiri, ubicados sobre los 4,500 metros de altitud y cuyas nacientes se encuentran en las lagunas de Lliullisqa y Sahuaccocha, respectivamente.

El río Negromayo tiene un recorrido de Sur a Norte, durante ese recorrido atraviesa por diversos pisos ecológicos que van desde los 4,800 hasta los 3,000 metros de altitud para luego desembocar en el río Mayobamba. El río además posee un cauce estacionario que aumenta durante los meses de febrero a abril y los reduce durante los meses de junio a octubre. Debido a su naturaleza topográfica, existen en las pendientes de ambas márgenes manantiales o puquios, los cuales permiten el crecimiento de pastizales para el ganado. De igual manera, los poblados y anexos distritales se abastecen del recurso hídrico mediante acequias y canales construidos en épocas prehispánicas como por ejemplo el canal de Puquioccta.

En su sección baja, el río forma un valle de tipo aluvial cuya extensión se encuentra dentro de la jurisdicción del actual distrito de Carmen Salcedo - Andamarca, provincia de Lucanas, región Ayacucho. La capital de este distrito se encuentra a 3,550 metros de altura y sus coordenadas UTM son: 8409574N y 0612300E; limitando por el Sur, Norte, Noreste y Noroeste con 


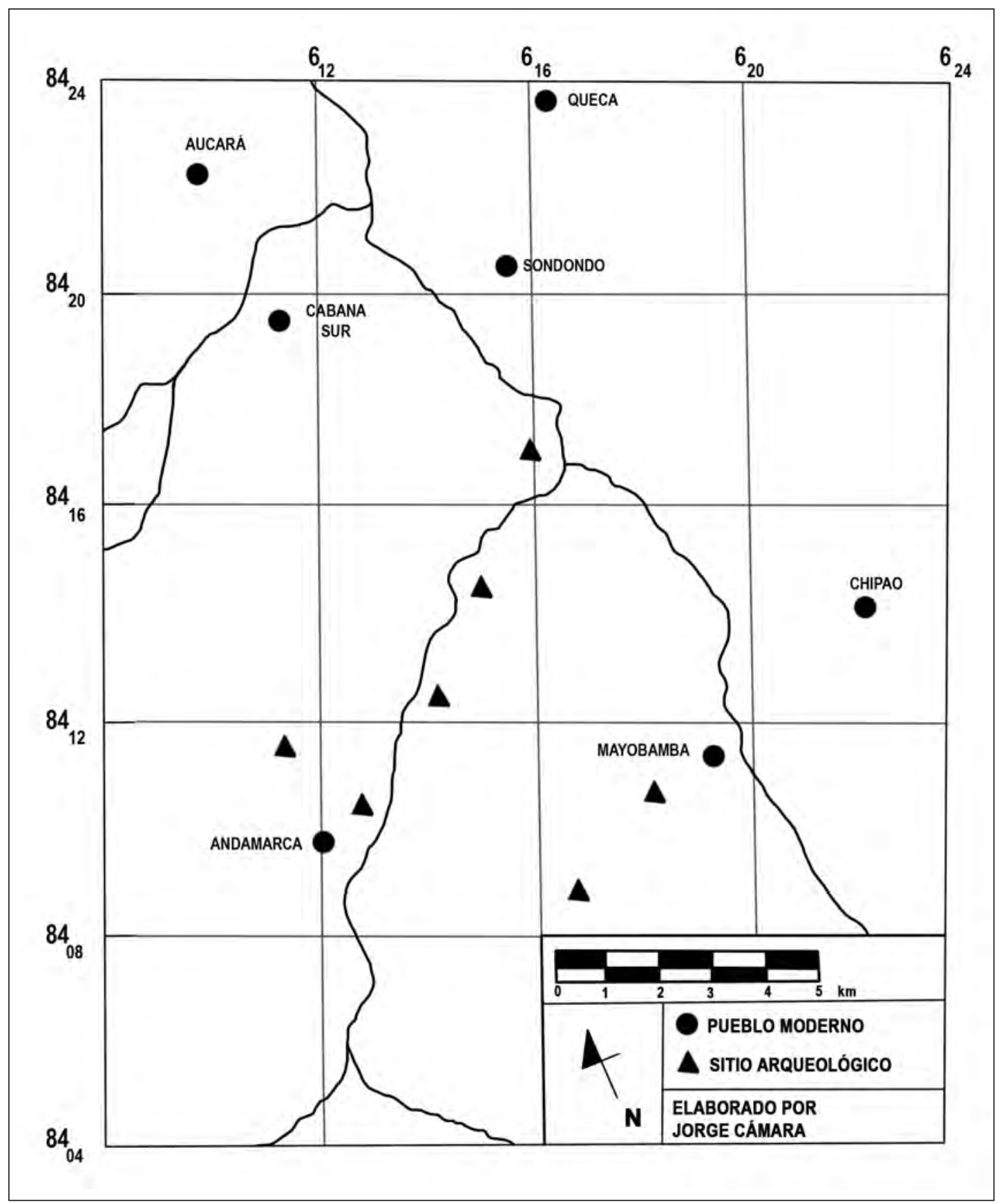

Figura 1. Mapa de la cuenca baja del río Negromayo con la ubicación de los yacimientos arqueológicos registrados hasta el momento. 


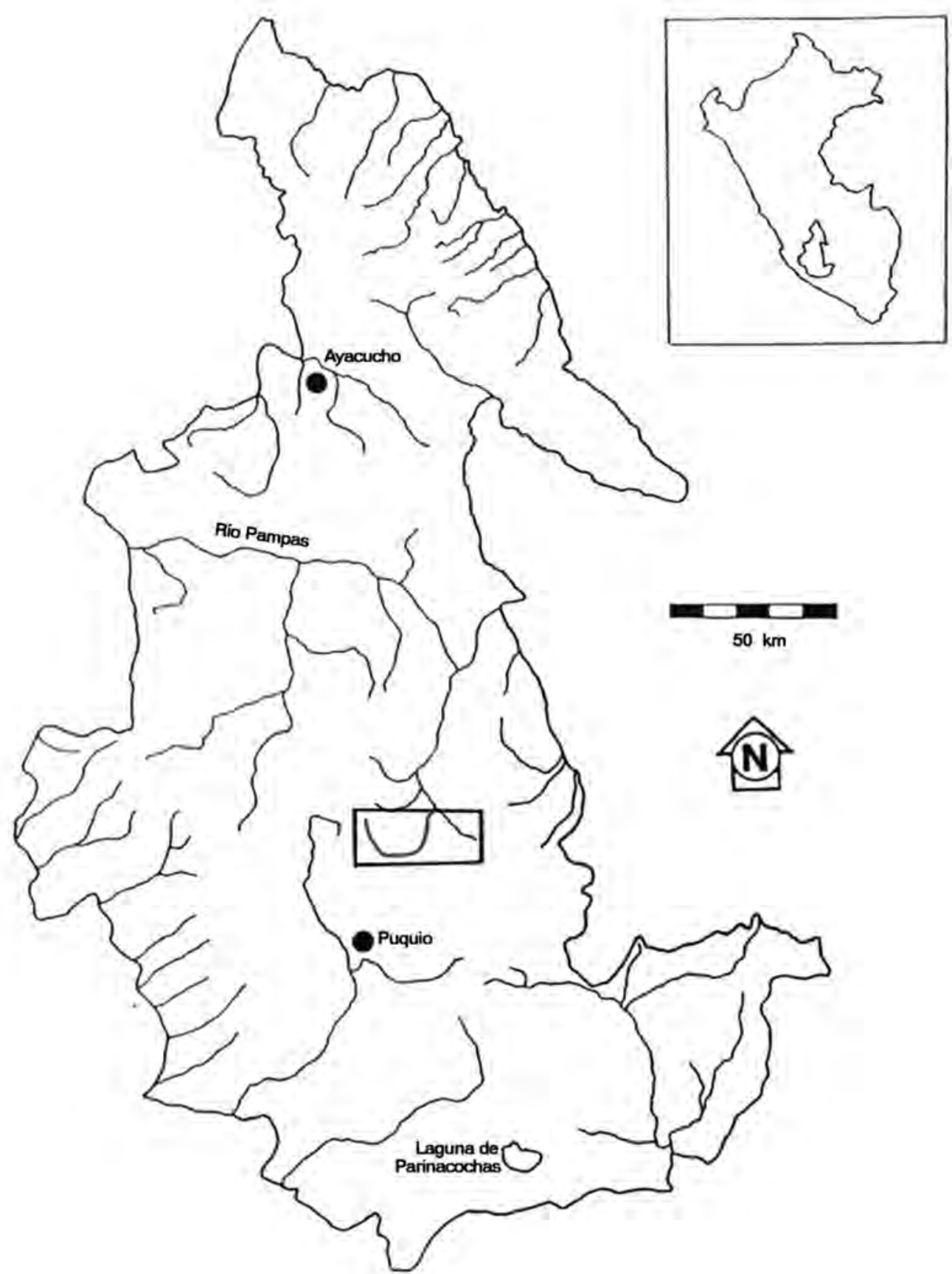

Figura 2. Ubicación de la cuenca del Negromayo en la región centro-sur de Ayacucho. Tomado y modificado de Schreiber 1992. 
los actuales distritos de: San Juan de Lucanas, Sondondo, Mayobamba y Cabana Sur, respectivamente. Este valle presenta además zonas estrechas y encañonadas, flanqueadas por laderas muy empinadas que han sido (re)utilizadas para fines agrícolas gracias a la innumerable cantidad de andenes que se observan a lo largo del valle. Estos andenes fueron probablemente construidos durante la época 2 del Horizonte Medio con la incursión de los Wari a la región (Schreiber 1987: 270).

La temperatura en esta sección del valle oscila entre los 6 y 20 $\mathrm{C}$ y las precipitaciones varían entre los 100 y 500 mm, anualmente. En esta sección del valle se pueden distinguir dos zonas ecológicas, (1) la ecozona de mayor elevación, la Suni, también llamada montano húmedo entre los 3,400 y 4,000 metros de altitud, la cual es identificada por el cultivo de tubérculos como la papa (Solanum tuberosum), el olluco (Ullucus tuberosus), la oca (Oxalis tuberosa), la maswa (Tropaeolum tuberosum), y además por el cultivo de la haba (Vicia faba), la alfalfa (Medicago sativa), la quinua (Chenopodium quinoa), entre otras leguminosas y algunas cactáceas y (2) la ecozona de menor elevación, la quechua, también llamada montano bajo, entre los 2,800 y 3,400 metros de altitud, la cual es identificada por el cultivo de maíz (Zea mays L.), cebada (Hordeum vulgare), trigo (Triticum spp.), tuna (Opuntia ficus indica), entre otras frutas de ambientes más cálidos, siendo el maíz el producto más importante y uno de los más variados en la región (Tosi 1960; Weberbauer 1945).

\section{Metodología de InVestigación}

Los datos en torno al asentamiento prehispánico de Canichi presentados y discutidos en este artículo han sido recuperados a partir de una prospección arqueológica que realizamos durante los meses de febrero a junio del presente año en la cuenca baja del río Negromayo. Dicha prospección se llevó a acabo como parte de una investigación de carácter regional que tiene como objetivo principal el explicar los cambios en la organización social, política y económica de los grupos sociales establecidos en la cuenca del río Negromayo durante los últimos períodos de ocupación prehispánica.

Sobre la base de las investigaciones arqueológicas acerca del desarrollo de las sociedades tardías en el valle del Carhuarazo (c.f. Schreiber 1987, 1993), planteamos una hipótesis a priori para llevar a cabo nuestra investigación. Dicha hipótesis plantea que “...los grupos sociales pertenecientes al período Intermedio Tardío (ca. 1000 - 1478 d.C.), deberían estar asentados en aldeas emplazadas en zonas estratégicas y de difícil acceso sobre los 3, 500 metros de altitud y cuya economía de subsistencia estaría basada en la producción agrícola, el pastoreo de camélidos y el aprovechamiento de recursos en zonas ecológicas complementarias por debajo de los 3,500 metros de altitud" (Cámara 2009: 6).

De esta manera el trabajo de campo a lo largo de la cuenca baja fue llevado a cabo por medio de una ficha de registro detallada donde se describió el entorno medioambiental en el cual se emplazó cada asentamiento, las relaciones entre las unidades arquitectónicas y los componentes espaciales inferidos a partir de las evidencias en superficie por medio del análisis intra-conjunto y del muestreo de tipo aleatorio simple.

Para el asentamiento de Canichi se elaboró un croquis referencial de ubicación utilizando las fotografías aéreas ampliadas a escala 1:2,000 (№ 18267 y 18268 del IGN) y se fechó relativamente por medio del material cerámico hallado en superficie. Con respecto al registro interno, se procedió a elaborar un levantamiento planimétrico en base al croquis general de ubicación con la ayuda de jalones, cinta métrica cordeles, nivel aéreo y brújula, además se contó con el apoyo de un grupo de estudiantes de la Universidad Nacional Mayor de San Marcos para 
realizar dicho trabajo. Una vez terminado el plano se procedió a sectorizar el asentamiento y a clasificar las estructuras arquitectónicas y los componentes espaciales. Así, se codificó al asentamiento de Canichi con el código NEG-1 por ser el primer sitio registrado durante nuestro trabajo de campo. Por otra parte los componentes arquitectónicos y espaciales se clasificaron por medio de la siguiente nomenclatura: R, X y P, donde $\mathrm{R}$ fue utilizada para asignar las unidades arquitectónicas de vivienda, las cuales son las más numerosas en el asentamiento, en tanto que $\mathrm{X}$ fue utilizada para asignar las estructuras funerarias, denominadas tradicionalmente Chullpas, y la letra P fue utilizada para asignar el espacio abierto o patio que conforma la aglomeración de las unidades arquitectónicas.

\section{EL ASENTAMIENTO PREHISPÁNICO DE CANICHI}

\section{UBICACIÓN, SECTORIZACIÓN Y CARACTERÍSTICAS ESTRUCTURALES}

El asentamiento prehispánico de Canichi se encuentra ubicado en la margen izquierda del río Negromayo emplazado sobre un promontorio rocoso muy cerca del actual pueblo de Carmen Salcedo - Andamarca a 3,530 metros de altitud (fig. 3), cuyas coordenadas UTM, tomadas de la parte central del asentamiento, son: $8410064 \mathrm{~N}$ y $0612696 \mathrm{E}$.

Este asentamiento presenta además una extensión aproximada de $21,000 \mathrm{~m}^{2}$ (2.1 ha) y se accede desde el lado Este del asentamiento por intermedio de un sendero prehispánico ela-

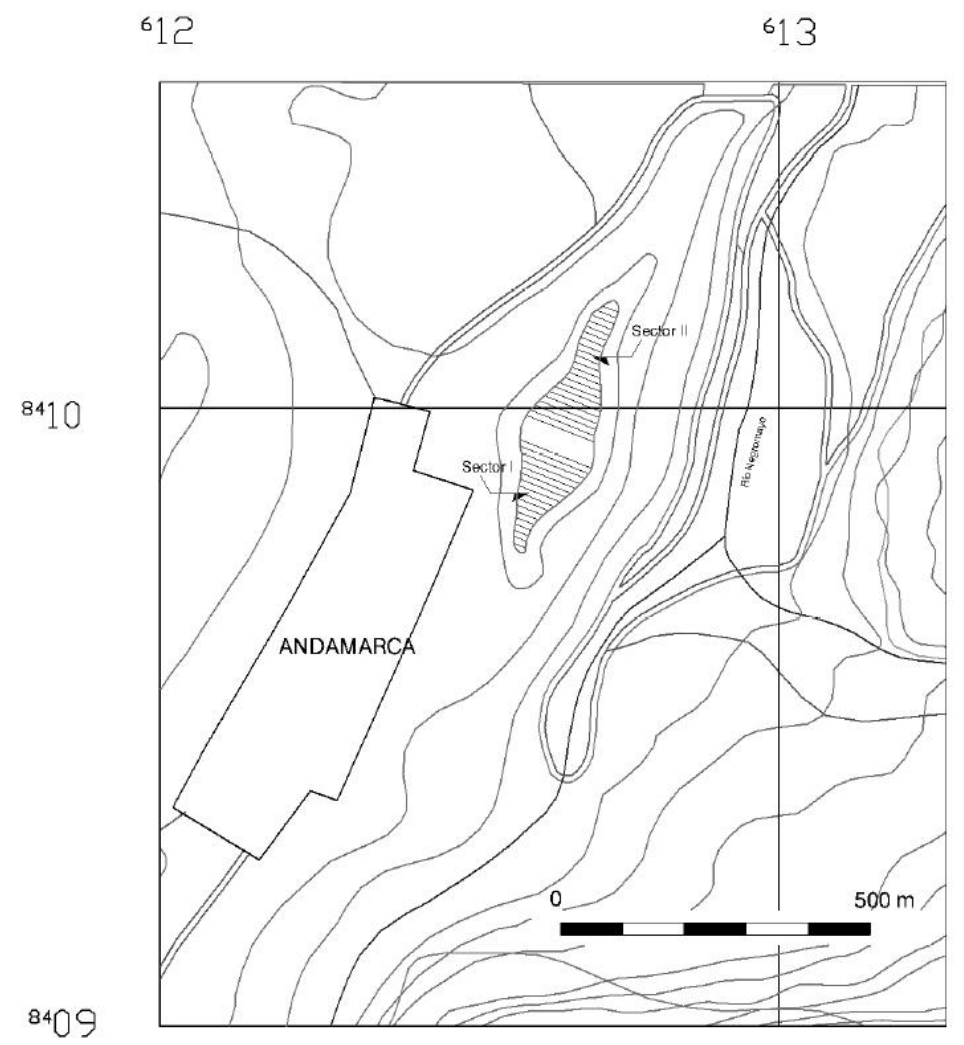

Figura 3. Sectorización propuesta para el asentamiento arqueológico de Canichi. 
borado a base de piedras y lajas que conecta la parte central del asentamiento con la rivera del río. Este sendero sería una extensión secundaria dentro de la red de caminos de tipo intervalle establecidos desde épocas del Horizonte Medio en la región (Schreiber 1991:247). (Fig. 4).

A diferencia de otros asentamientos registrados a lo largo de la cuenca baja, Canichi es uno de los pocos ubicados en una zona de amplia visibilidad y fácil acceso, donde las pendientes son menos pronunciadas y las unidades arquitectónicas se encuentra edificadas sobre terrazas artificiales que han sido construidas para aprovechar las zonas no aptas para el cultivo. Estas características en torno a la ubicación del asentamiento quizá respondan a actividades agrícolas pues se asocian a este asentamiento andenes de una considerable extensión, característica que está ausente en otros asentamientos ubicados a lo largo de la cuenca baja.

Sobre la base de esta descripción acerca de la ubicación en el espacio y para realizar un mejor registro de campo, el asentamiento fue sectorizado en dos áreas de acuerdo a sus características topográficas, variabilidad de las estructuras arquitectónicas y densidad del material cultural asociado. Estos sectores han sido denominados: NEG-1A y NEG-1B.

\section{SECTOR NEG-1A}

Este sector se encuentra ubicado en la parte más elevada del promontorio natural a 3,526 metros de altitud y está constituido por la mayor cantidad de estructuras arquitectónicas y la mayor densidad de material cultural en superficie.

En su lado Noreste el asentamiento presenta tres muros consecutivos de aproximadamente $90 \mathrm{~cm}$ de ancho, los cuales se proyectan alrededor del asentamiento. Estos muros han sido edificados especialmente para soportar el peso de las unidades arquitectónicas edificadas sobre las terrazas artificiales debido a lo accidentando de la topografía de este sector en comparación con el lado Noroeste del asentamiento, pues la topografía es menos accidentada por su cercanía al pueblo. La técnica constructiva utilizada para la edificación de estos muros consta de una doble hilera de piedras canteadas sin labrar unidas con argamasa de barro.

En este sector se han identificado alrededor de 30 unidades arquitectónicas, las cuales constan de una sola estructura de planta circular cuyos diámetros varían de 2.5 a 4.5 m. Estas estructuras presentan un solo vano de acceso de $60 \mathrm{~cm}$ de ancho x $1.20 \mathrm{~m}$ de alto, los cuales no presentan una uniformidad en su orientación (fig. 5).

La altura promedio de estas estructuras es de $1.8 \mathrm{~m}$, además los muros que la conforman tienen anchos que varían entre los 40 y $60 \mathrm{~cm}$ con una ligera inclinación hacia el interior de los recintos. En la parte interna, algunas de las estructuras presentan divisiones y en algunos casos nichos de $20 \mathrm{~cm}$ de largo x $30 \mathrm{~cm}$ de alto. (Fig. 6). El material constructivo utilizado para la edificación del asentamiento es principalmente local, utilizando piedras de canteado rustico sin labrar, estos fueron unidas con una argamasa elaborada a base de barro, cal y algunas fibras vegetales y restos de cerámica y obsidiana para darle consistencia.

$\mathrm{Al}$ igual que en otras regiones de la sierra andina, estas unidades conforman un patrón arquitectónico que ha sido denominado "grupo de patio" o "unidad alveolar", el cual está conformado por una o más estructuras dispuestas alrededor de un espacio central abierto (c.f. Bonnier 1997; DeMarrais 2001; Lavallée y Julien 1987). En este sector la disposición de las estructuras está conformada principalmente por dos y hasta cinco recintos ubicado alrededor del espacio central abierto, el cual varía de 5 a $10 \mathrm{~m}$. de extensión (fig. 7). Asociadas a estos recintos se encuentra estructura, también de planta circular pero completamente techada y edificadas con la técnica constructiva de la "falsa bóveda" 


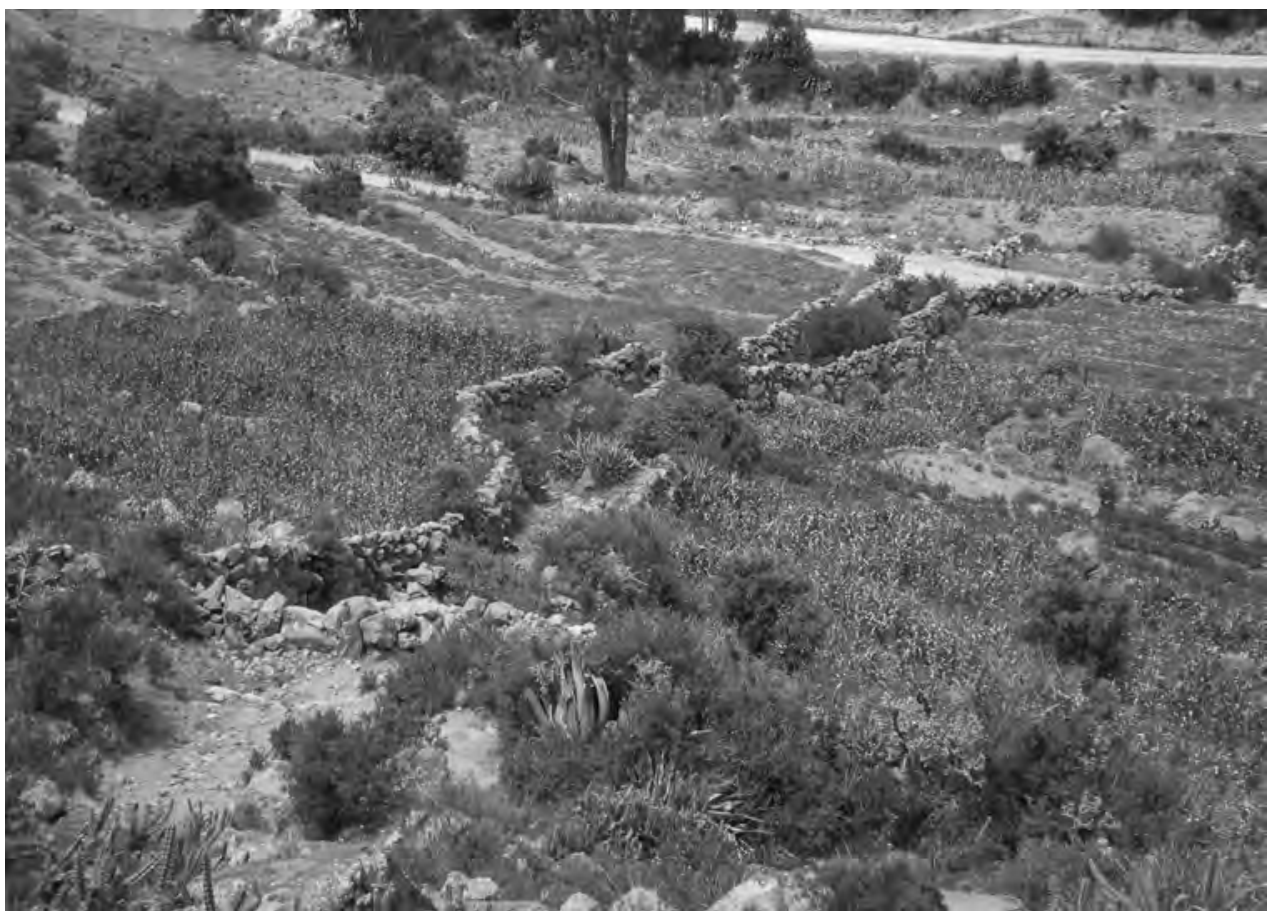

Figura 4. Vista general de la ubicación del sendero de acceso en el lado este del asentamiento.

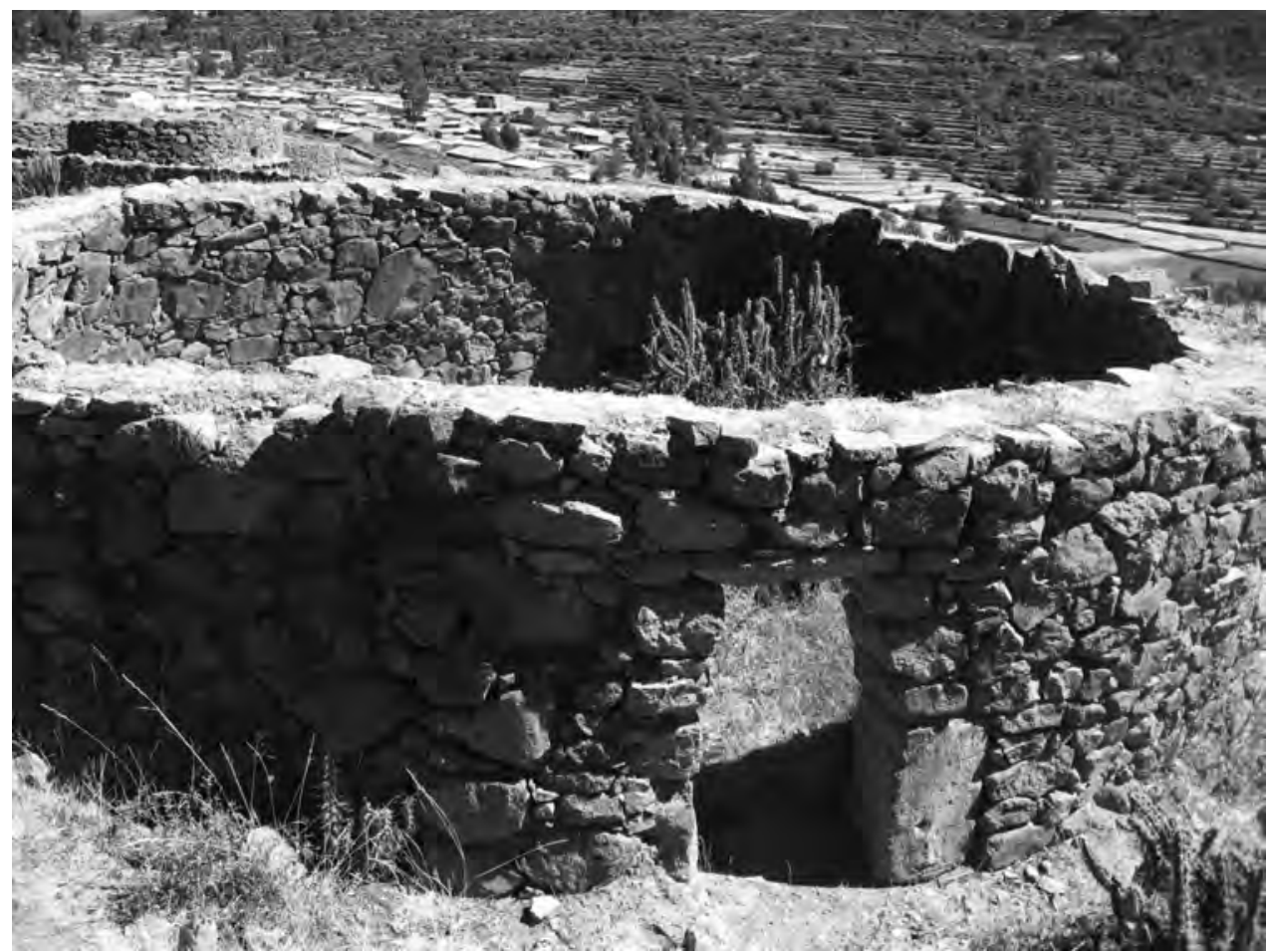

Figura 5. Detalle de una unidad arquitectónica de vivienda con planta circular ubicada en el sector 1A. 
cuyos diámetros varían de 1.5 a $3 \mathrm{~m}$ y con una altura promedio de $1.8 \mathrm{~m}$ (Fig. 8). Estos conjuntos se encuentran interconectados por calles y pasajes de 1 a $2 \mathrm{~m}$ de ancho, por donde pueden transitar hasta 4 personas a la vez sin que haya alguna incomodidad, esta característica advierte un área de tránsito libre.

En la parte alta de este sector se encuentran también recintos de planta circular, pero estos, a diferencia de los ubicados en la parte baja, presentan diámetros que varían de 9 a $12 \mathrm{~m}$, y alturas de 1.8 a $2.5 \mathrm{~m}$. En este tipo de recintos se encuentran nichos de $20 \mathrm{~cm}$ de largo x $30 \mathrm{~cm}$ de alto. Estas estructuras presentan una conformación de doble hilera como técnica constructiva y están asociados directamente con una estructura de planta rectangular, la cual difiere, tanto en el material constructivo como en el acabado.

Esta edificación ha sido caracterizada por Schreiber (1993: 97) como una posible estructura de función administrativa Inka, por lo cual se asume que es posterior a las estructuras edificadas en la parte baja. El material cerámico encontrado en superficie durante nuestro reconocimiento corrobora la hipótesis de Schreiber, pues la mayoría corresponde al estilo Inka, tanto imperial como provincial.

Finalmente, en la parte más septentrional de este sector se encuentran dos muros consecutivos, los cuales presentan una orientación $\mathrm{NE}$ - SW, una altura aproximada de $4 \mathrm{~m}$ y una extensión de 14 m de largo (fig. 9). Estas estructuras son las más prominentes de todo el asentamiento y al parecer se encuentran cimentadas desde la base del promontorio por lo que creemos que dichos muros estarían asociados directamente con las terrazas agrícolas ubicadas en la parte más baja del asentamiento. Su función aún no es clara para nosotros.

Figura 6. Detalle de un nicho en la parte interna de una unidad arquitectónica de vivienda ubicada en el sector $1 \mathrm{~A}$.

\section{Sector NEG-1B}

Ubicado en la parte más baja del promontorio natural a 3,495 metros de altitud, este sector presenta una mayor extensión que el anterior, sin embargo presenta una menor densidad, tanto en estructuras arquitectónicas como en material cultural. Desde el punto de vista superficial es muy difícil plantear ideas con relación a la funcionalidad y disposición de las estructuras debido a que la mayor parte del sector ha sido reconstruido, alterando el estado original del asentamiento, sin embargo quedan algunas estructuras que no han sido reconstruidas.

En este sector se han identificado solamente 20 unidades arquitectónicas, las cuales constan, al igual que en el sector $1 \mathrm{~A}$, de una sola estructura de planta circular, cuyas dimensiones varían de 2 a 4 m de diámetro y su altura promedio es de $1.8 \mathrm{~m}$, con muros ligeramente inclinados hacia la parte interior del recinto. Estos muros presentan un ancho promedio de $60 \mathrm{~cm}$ y han sido elaborados a base piedras de canteado

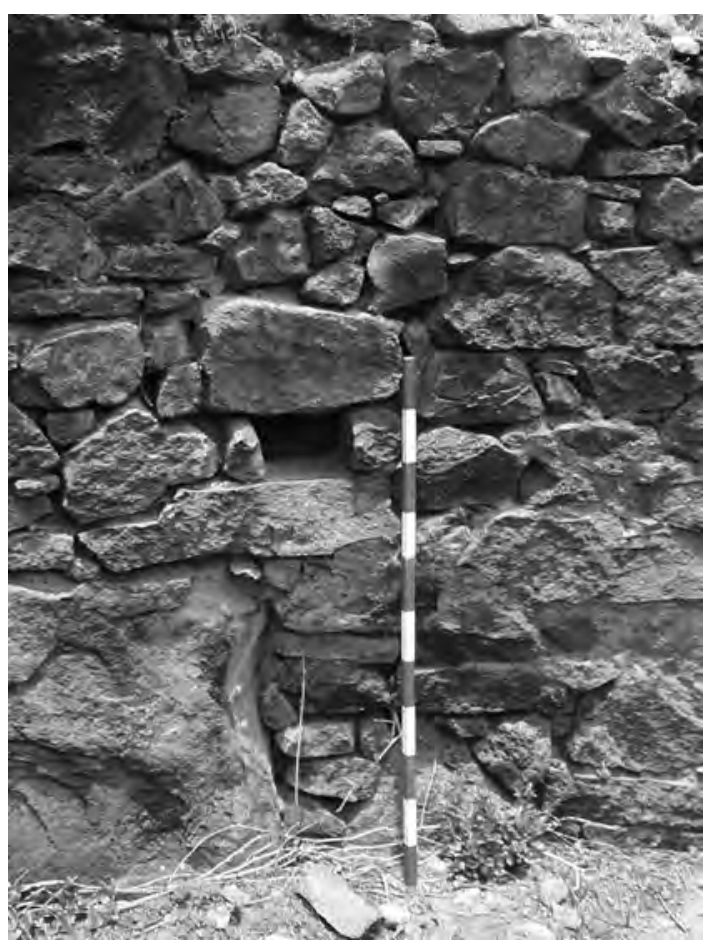




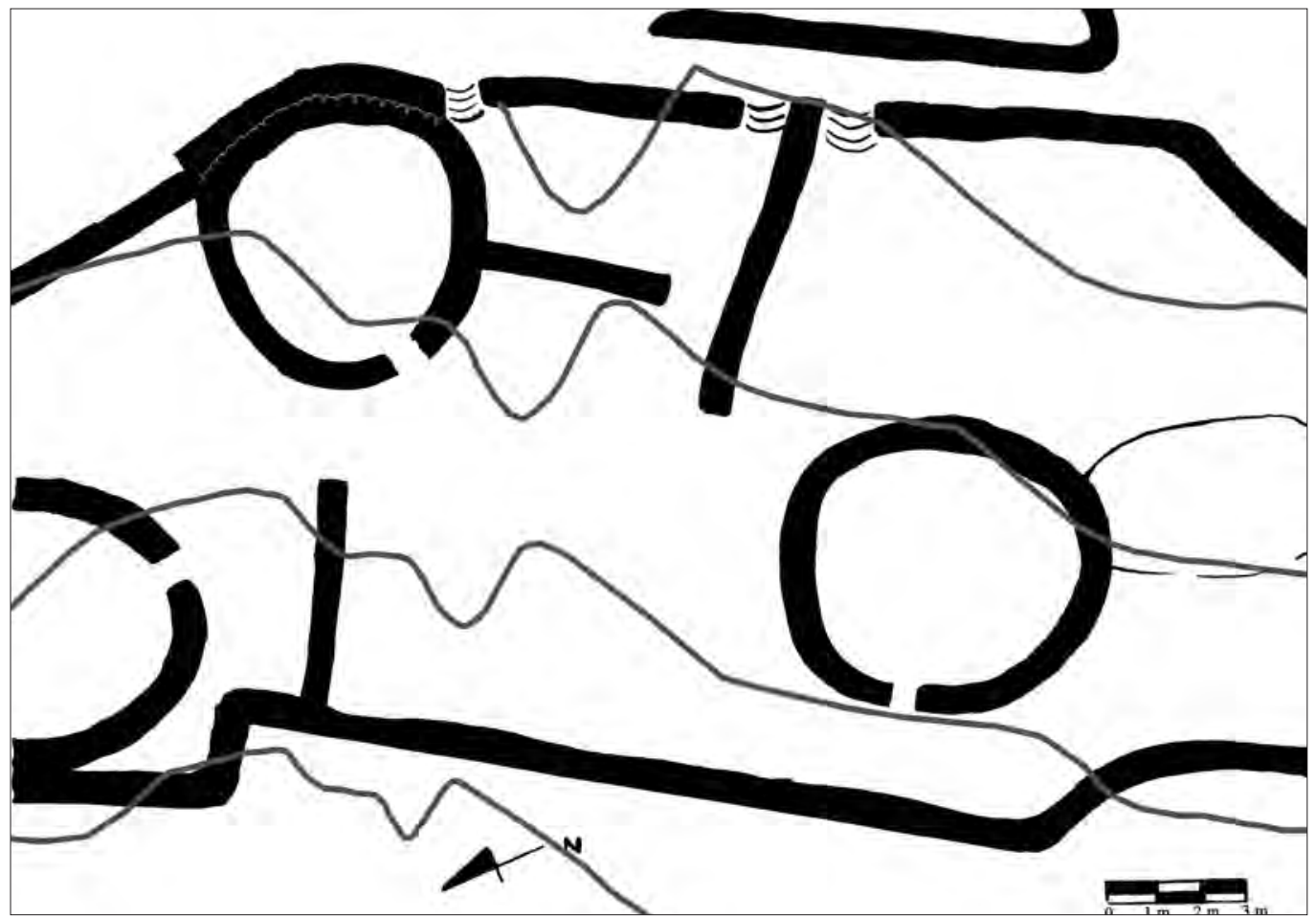

Figura 7. Plano de distribución arquitectónica en el sector 1A, obsérvese la aglomeración de las unidades arquitectónicas formando un espacio abierto o patio.

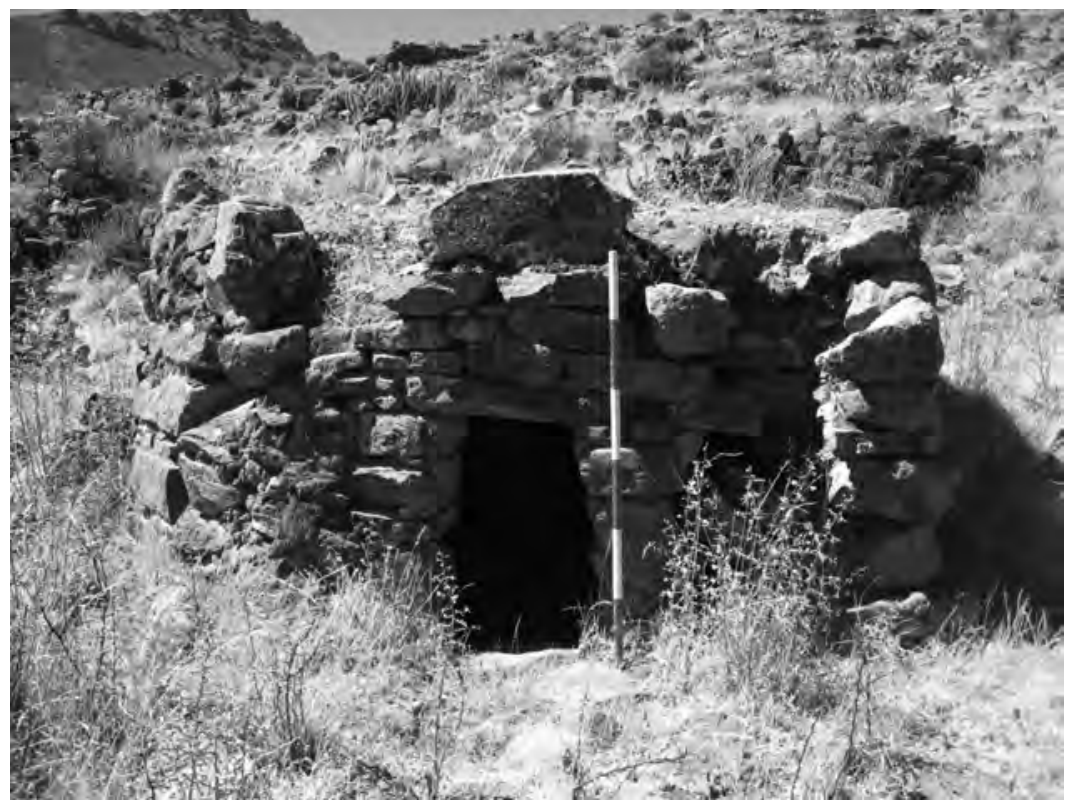

Figura 8. Detalle de una unidad arquitectónica techada, tradicionalmente llamada Chullpa, en el sector 1A. 
rústico sin labrar unidas con argamasa de barro. Estas unidades también presentan un solo vano de acceso de $60 \mathrm{~cm}$ de ancho x $1.20 \mathrm{~m}$ de alto; cabe resaltar que ninguna de las unidades registradas presenta alguna división interna al igual que nichos o alguna otra decoración.

Las unidades arquitectónicas registradas en este sector presentan también el patrón del "grupo de patio", sin embargo debido a la alteración que ha sufrido este sector sólo se pueden identificar algunos conjuntos habitacionales los cuales están conformados por dos y hasta cuatro recintos dispuestos alrededor del espacio abierto, el cual mide aproximadamente $6 \mathrm{~m}$ de extensión (fig. 10). A estas unidades se asocian también las estructuras techadas de planta circular, las cuales presentan en algunos casos hasta dos piezas arquitectónicas conjuntas.

En ambos sectores no se han registrado mu- ros ni zanjas, componentes arquitectónico característicos de los asentamientos tardíos en la sierra central, los cuales cumplieron funciones defensivas (Bonnier 1997: 31). Esta característica en conjunto con la asociación de estructuras tipo Chullpas a los conjuntos habitacionales muestran lo particular de la región, pues no sólo en Canichi se han registrado estas características; las investigaciones realizadas por Schreiber en el valle del Carhuarazo muestran también una recurrencia en este patrón para las épocas tardías (Schreiber 1987:274).

\section{MATERIALES ASOCIADOS}

Durante el registro del asentamiento se observó una gran cantidad de material cultural en superficie siendo de mayor predominancia la cerámica, sin embargo se ha observado además, artefactos y desechos de material lítico. Como

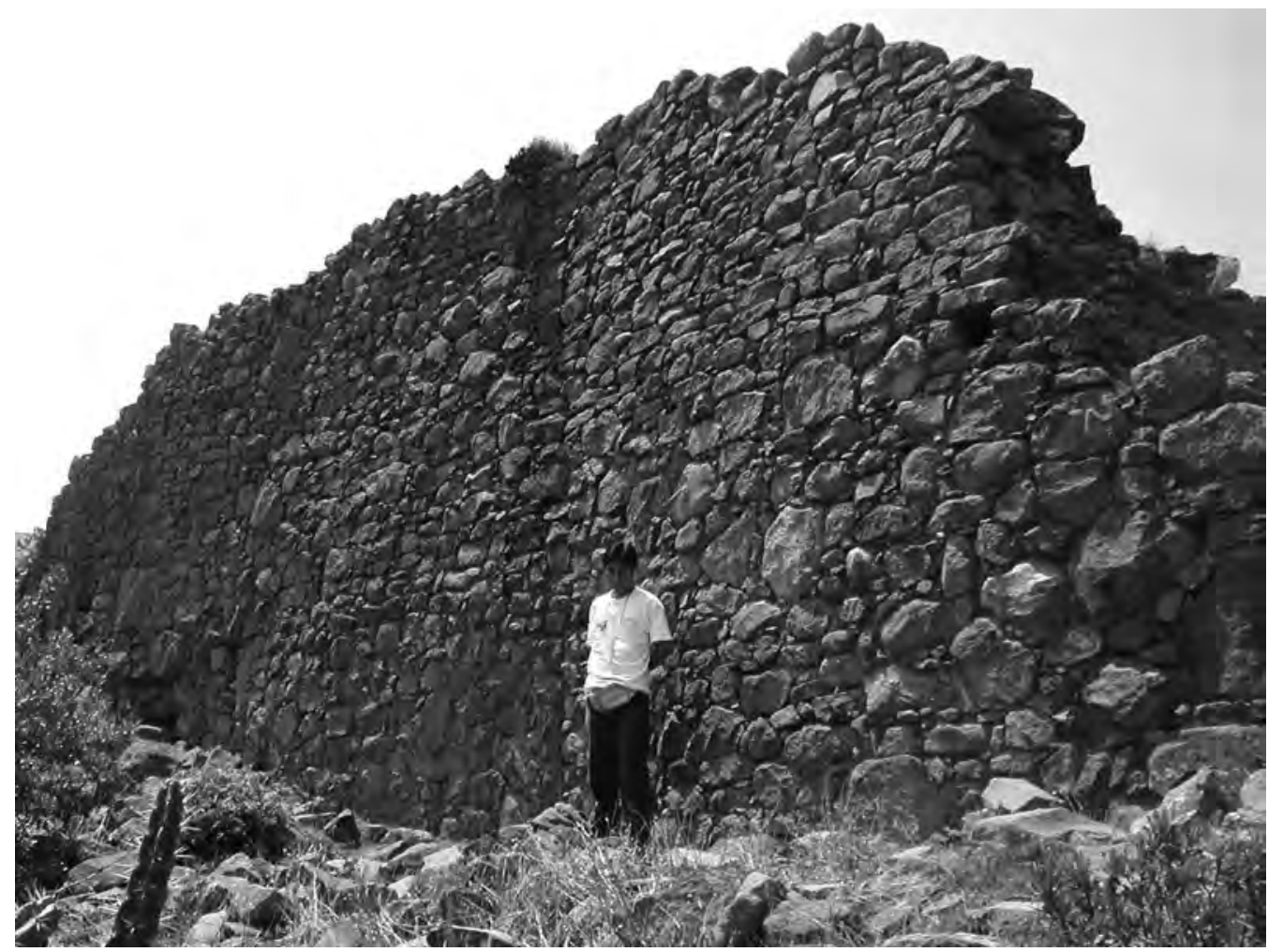

Figura 9. Detalle del primer muro de gran tamaño ubicado en la parte más septentrional del asentamiento. 
habíamos mencionado en la metodología, se ha tratado de ser lo más responsable en el registro, por lo que se ha realizando un muestreo aleatorio simple para la recolección y análisis de los materiales. Este muestreo se realizó partiendo de la sectorización y clasificación de los componentes arquitectónicos y espaciales, recolectando así el material del interior de los recintos y de los espacios abiertos o patios.

De manera general, la cerámica registrada en el asentamiento de Canichi corresponde, según la clasificación de Schreiber para el valle del Carhuarazo, a los períodos Marke, Toqsa y Jasapata $^{1}$ (Schreiber 1992:135, fig. 11). La mayor concentración de material cerámico se encuentra en el sector $1 \mathrm{~A}$ y pertenecen las dos últimas fases de la mencionada clasificación. (Figs. 12 y 13).
Las formas más comunes dentro del corpus cerámico perteneciente a estos períodos son cuencos (en mayor cantidad), platos, ollas y cántaros, los cuales presentan una decoración pictórica y un acabado medio ${ }^{2}$; estos fragmentos fueron recolectados mayoritariamente dentro de los recintos. En menor cantidad se han registrado fragmentos que pertenecen al período Marke (Schreiber 1993:80), cuyas formas más comunes son cuencos de bordes engrosados y una botella con decoración pictórica en dicha parte de la vasija, estos fragmentos han sido hallados en los rellenos de algunos muros que en algún momento colapsaron (Fig. 14).

La cerámica de estilo Inka hallada en este asentamiento se presenta en menor proporción que las pertenecientes a la tradición local. El material cerámico se encuentra, de manera exclusi-

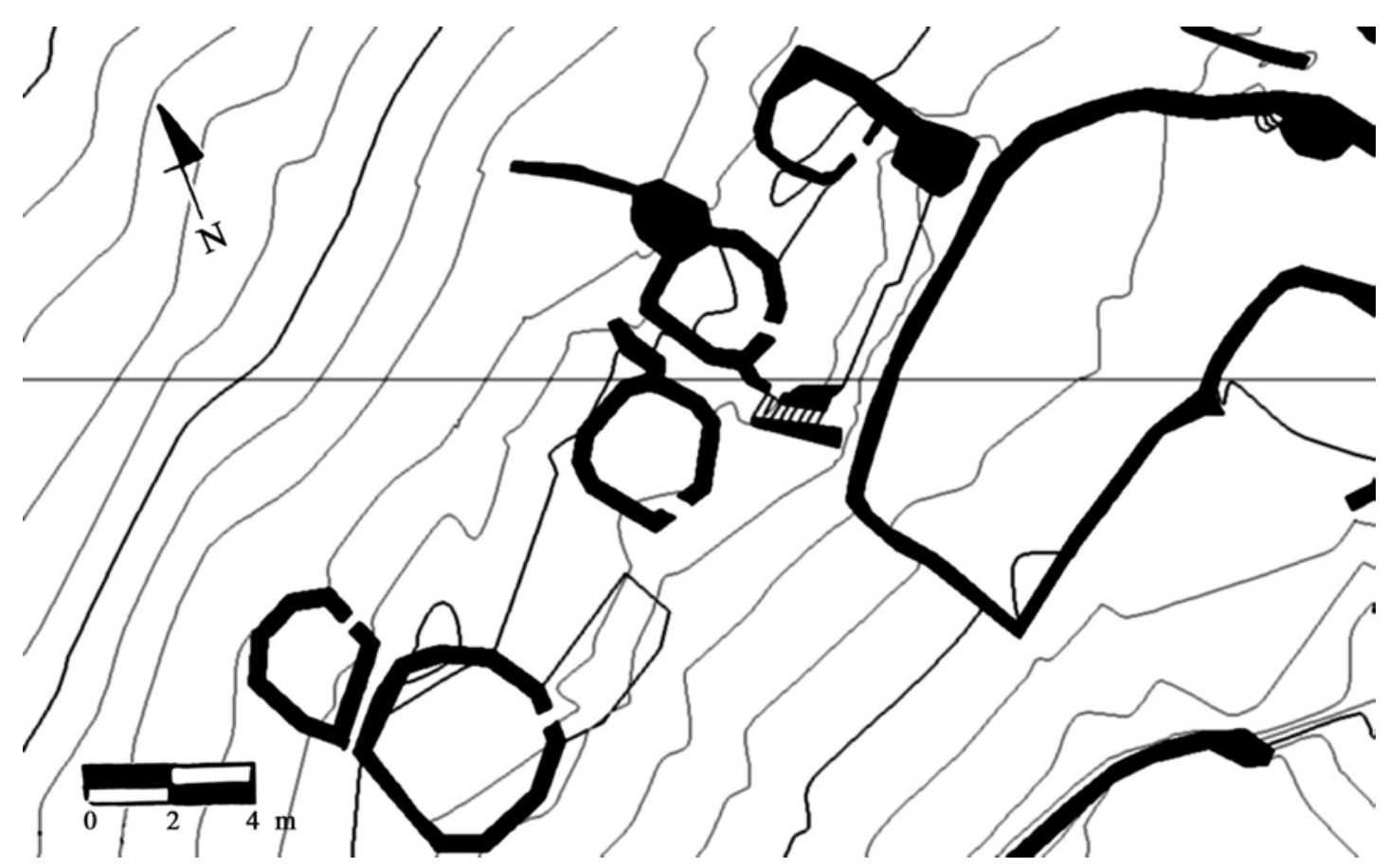

Figura 10. Plano de distribución arquitectónica del sector 1B.

1 Para mayor detalle sobre la secuencia estilística y cronológica del valle del Carhuarazo para estos períodos revisar el trabajo de Schreiber (1993:80-81).

2 Para una mejor aproximación de las características morfológicas del material cerámico de este asentamiento revisar el trabajo de Sonia Berrocal en este volumen. 
va, en la parte más elevada del sector NEG-1A. La muestra recolectada se puede dividir en dos grupos, el Inka imperial y el Inka provincial ${ }^{3}$, cuyas formas más comunes son ollas, cántaros y platos (Fig. 15).

Se han hallado además evidencias de torteros, los cuales han sido elaborados a partir de fragmentos de cerámica, desechos y algunos fragmentos de cerámica con claras evidencia de cocción fallida, lo cual advierte una posible elaboración de dichos artefactos en ciertos espacios del asentamiento en particular pues todas estas evidencias han sido halladas en los espacios abiertos y no dentro de los recintos.

Como mencionamos al inicio de este apartado, además de cerámica hemos regis-

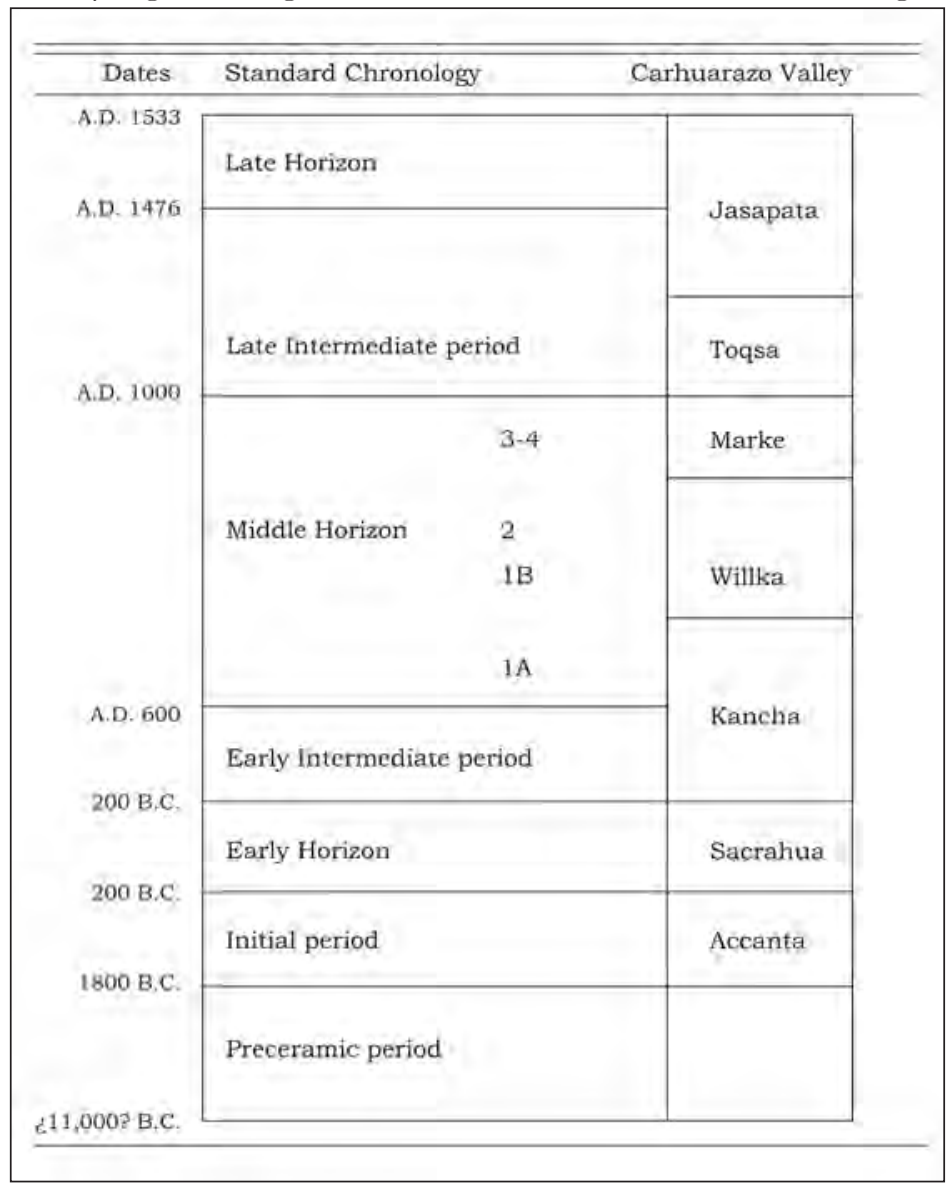

trado significativas cantidades de artefactos líticos a lo largo del asentamiento. En su mayoría estos artefactos son de molienda como batanes, manos de moler y morteros, los cuales han sido elaborados con materiales locales traídos probablemente de la rivera del río y de Campanero, una cantera que al parecer habría sido utilizada durante épocas prehispánicas (Cámara 2009:25-26, fig. 16).

Finalmente, se ha observado también la presencia artefactos y desechos de obsidiana (fig. 17), cuyo origen geológico habría estado localizado en la cantera de Jampatilla, la cual habría sido explotada por las poblaciones locales siendo el rango de distribución el valle de Carhuarazo pues no se han encontrado evidencias de dicha materia prima en otras zonas de Ayacucho (Burger et al. 1998: 230) en comparación con la cantera de Quispisisa, la cual abasteció a muchas regiones de los Andes Centrales debido a sus características geológicas (Burger 2006: 429).

Figura 11. Secuencia cronológica del valle del Carhuarazo (Sondondo). Tomado de Schreiber 1992:135.

3 La división en estos dos grupos se basa principalmente en los criterios utilizados por Terence D’Altroy y su equipo de investigación, los cuales han sido identificados a partir de sus investigaciones en la región de Jauja y el Noreste de Argentina. De esta manera, siguiendo el planteamiento de D'Altroy, el Inka Imperial corresponde directamente a las vasijas importadas desde la capital cuzqueña en los diferentes estilos identificados por Rowe, mientras que el Inka Provincial corresponde a las vasijas que imitan a la Imperial en morfología, diseños iconográficos y en la estructura del diseño pero que han sido producidas en la Provincia (D’Altroy et al. 1994:409). 

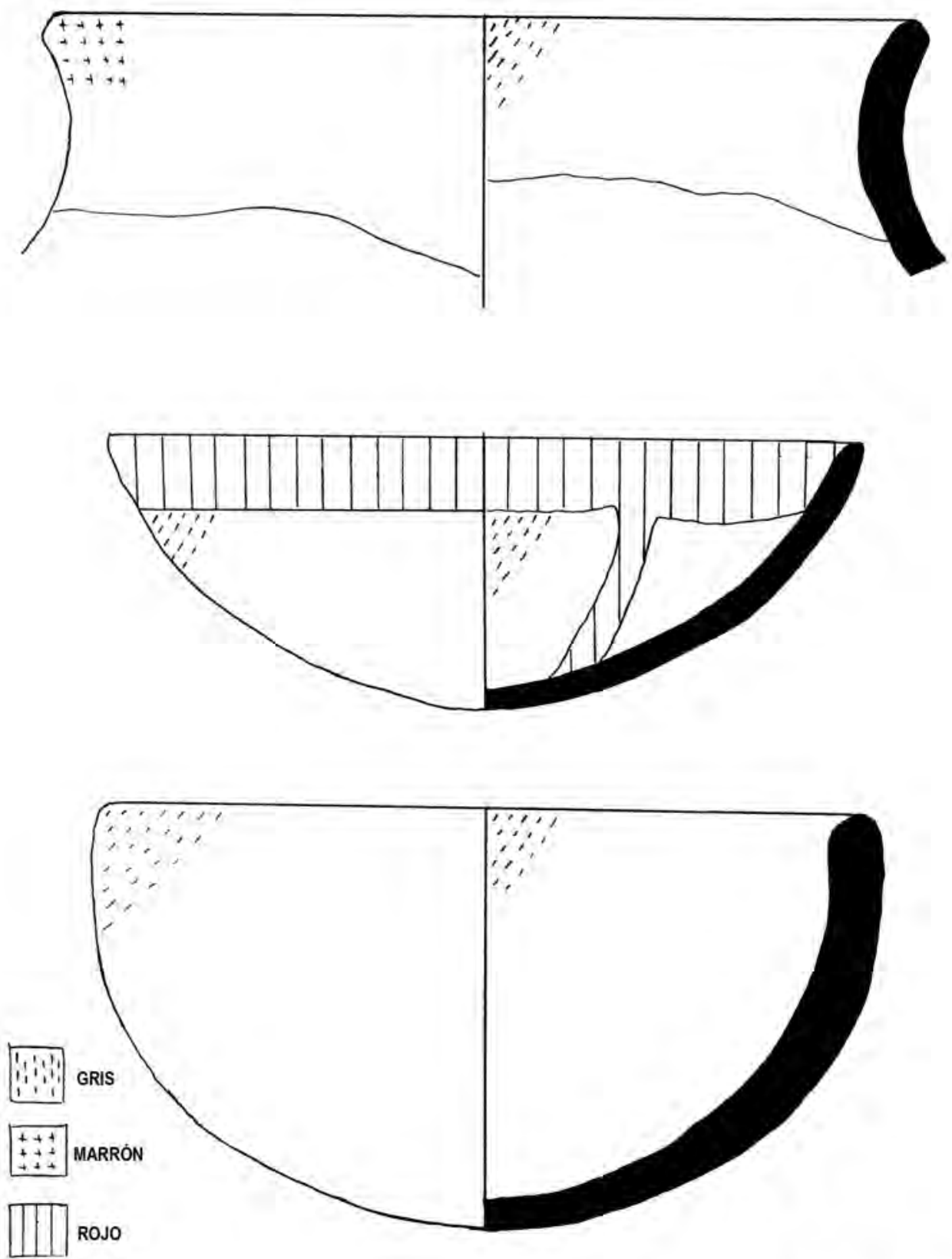

$\because \vdots$ ANARANJADO

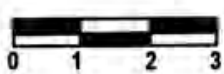

NEGRO

Figura 12. Formas reconstruidas de cerámica perteneciente a la fase Toqsa. 


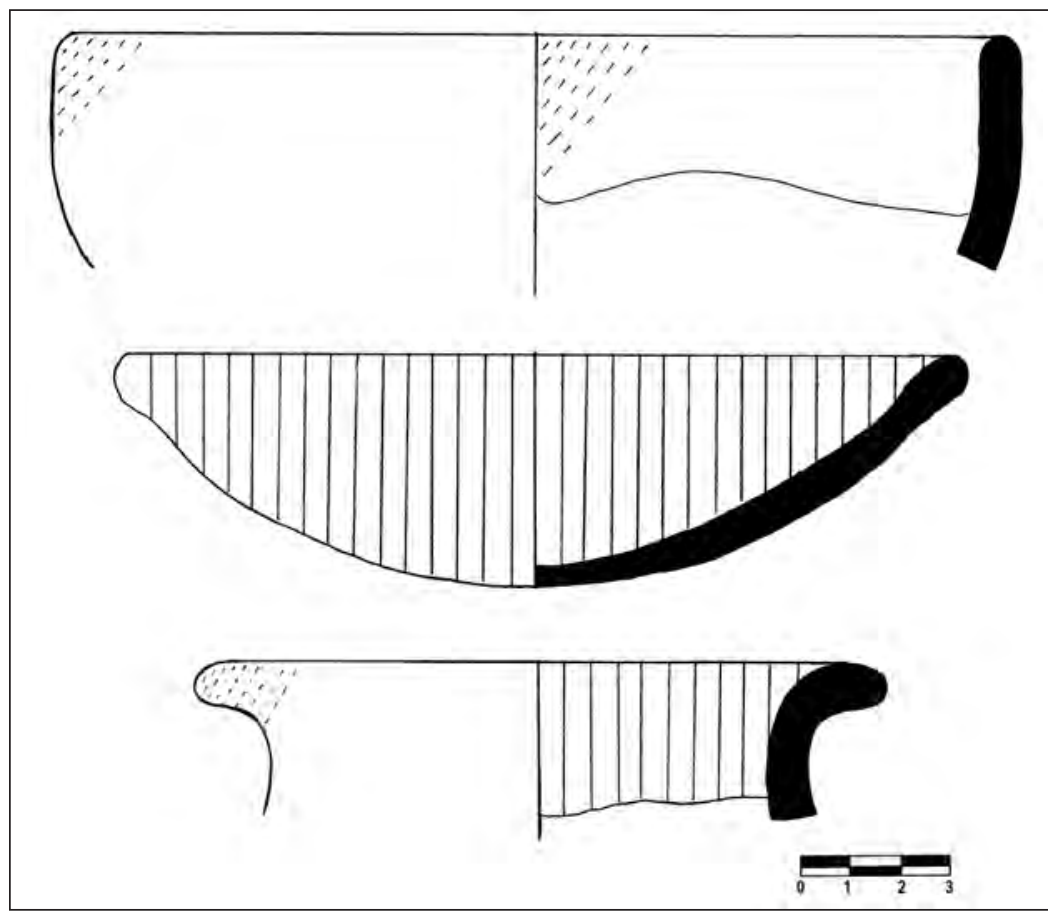

Figura 13. Formas reconstruidas de cerámica perteneciente a la fase Jasapata.

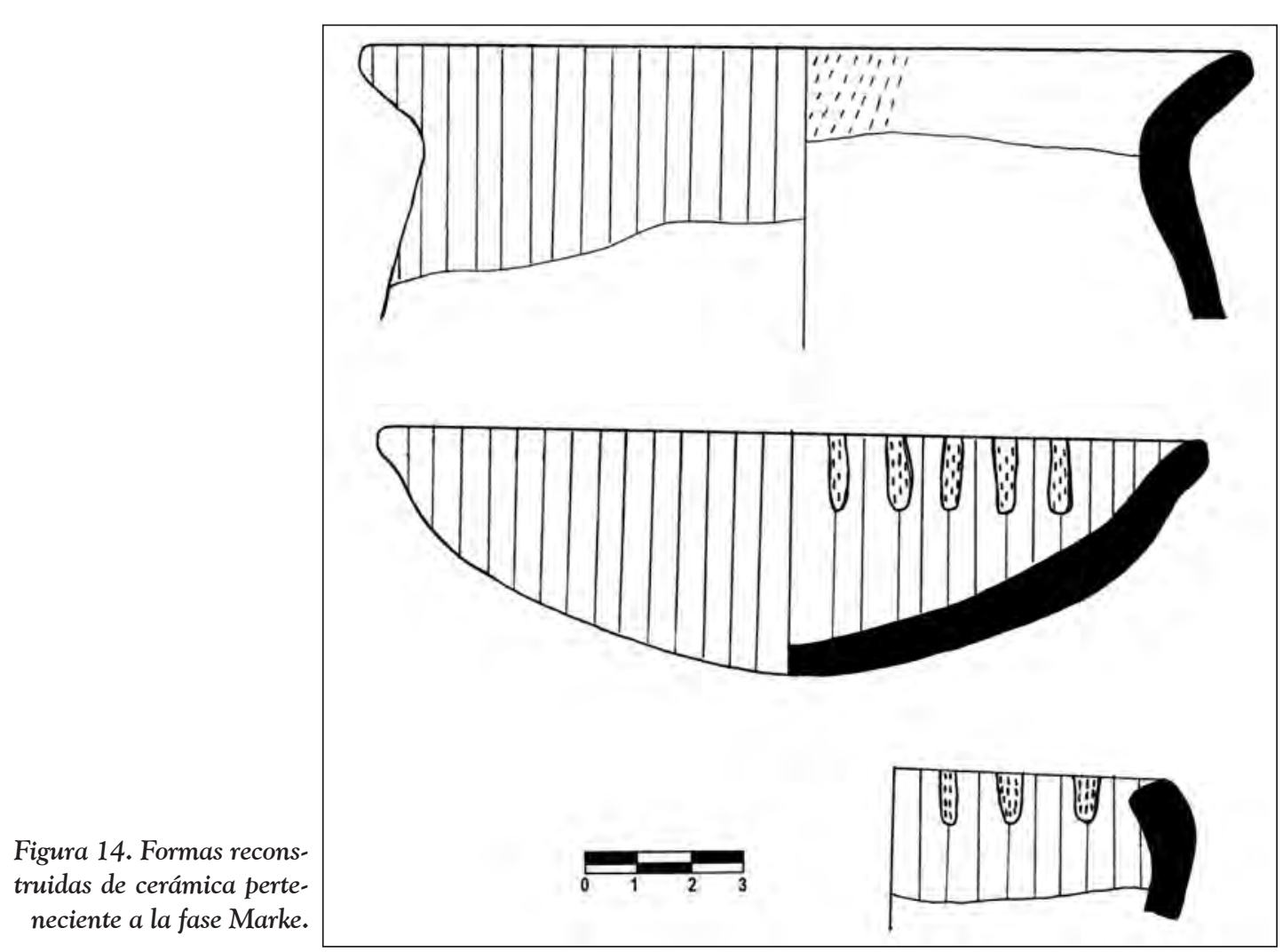




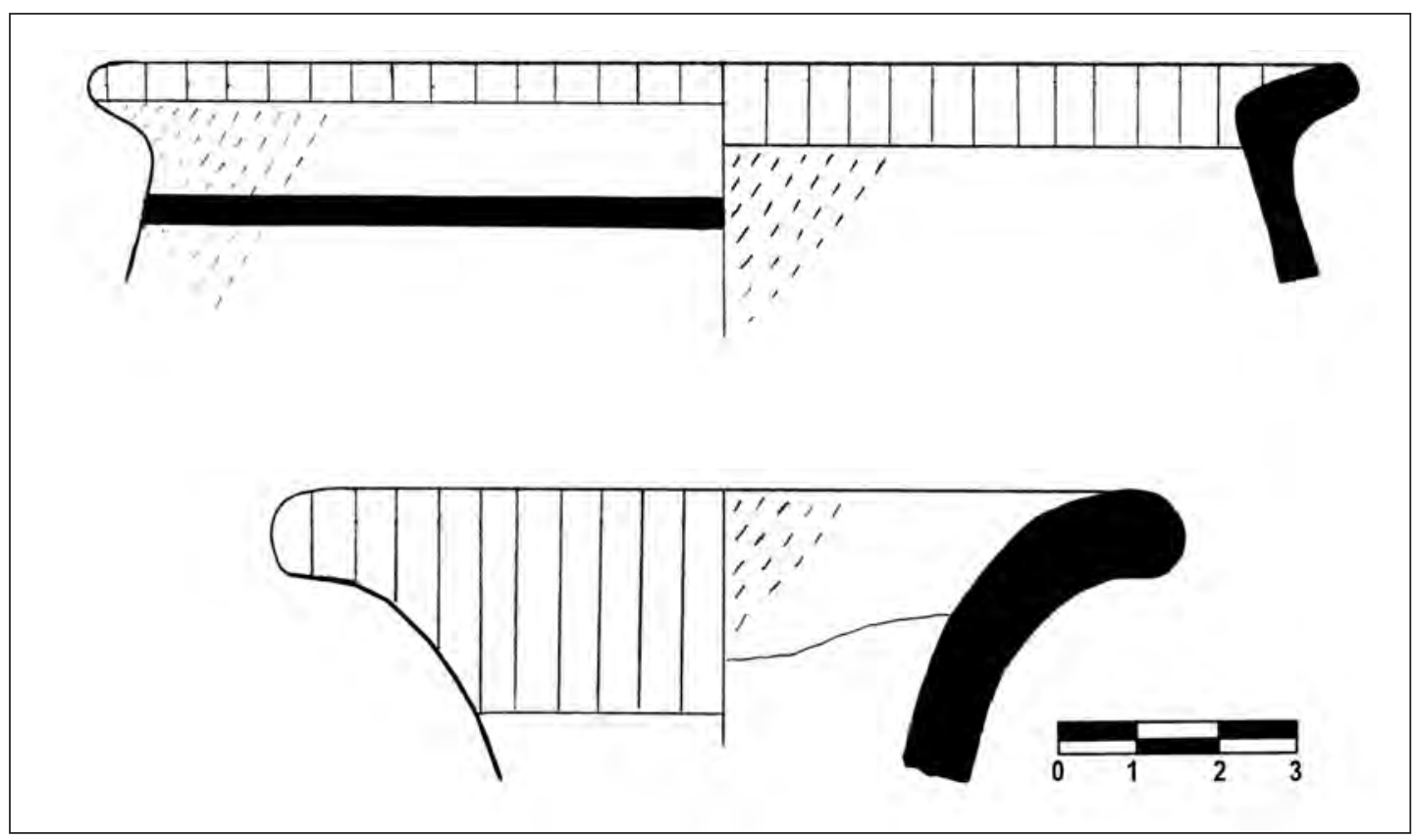

Figura 15. Formas reconstruidas de cerámica Inka hallada en Canichi.

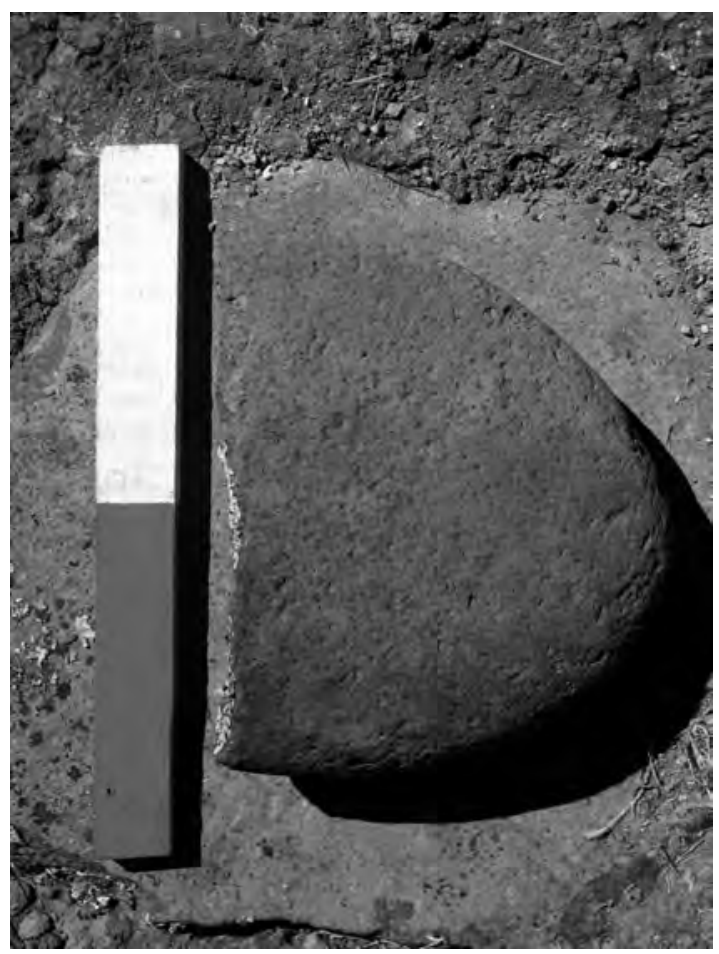

Figura 16. Mano de moler encontrada en uno de los recintos de vivienda en el sector $1 \mathrm{~A}$.

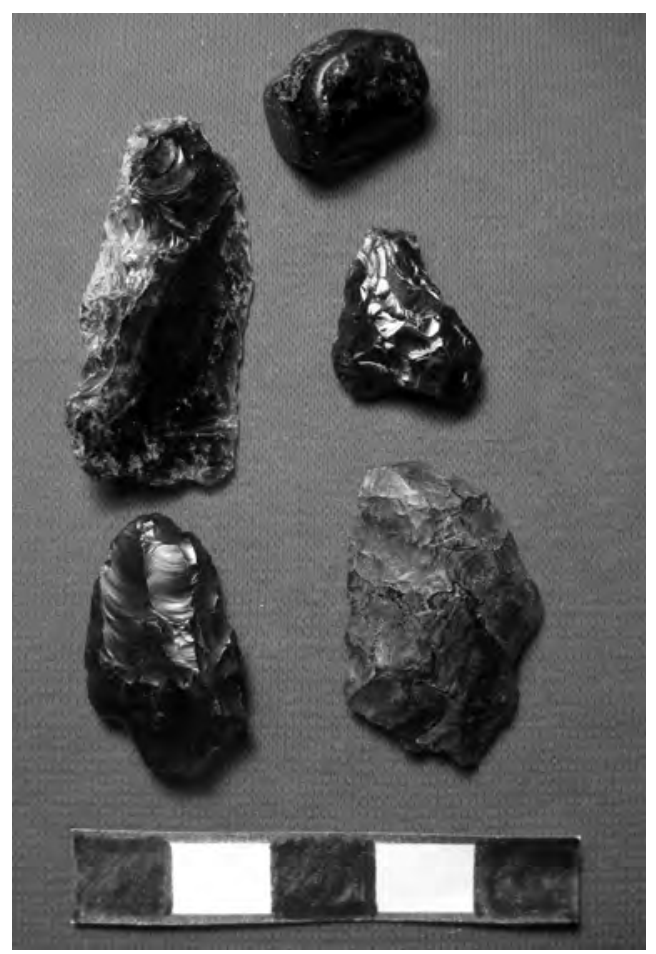

Figura 17. Restos de talla de material de obsidiana hallados en Canichi. 


\section{DISCUSIÓN}

\section{Problemas CRONOLÓGicos}

Las evidencias arqueológicas registradas hasta el momento en Canichi guardan relación directa con patrones y sistemas de asentamiento característicos de los períodos tardíos, sin embargo la falta de excavaciones sistemáticas no nos permiten, por el momento, establecer variabilidades temporales específicas. A pesar de esto, trataremos de discutir este problema sobre la base de las evidencias recuperadas durante nuestro reconocimiento para caracterizar una región que, desde nuestro punto de vista, difiere de las generalidades establecidas para la región de Ayacucho como parte integral de la denominada confederación Chanka.

Debido a la carencia de secuencias estratigráficas confiables y fechados de C14 es complicado establecer rangos cronológicos precisos sólo con evidencia arquitectónica, pues a lo largo de la sierra central, para los períodos tardíos, el patrón de recintos aglomerados o unidades alveolares asociados a un espacio abierto se ha generalizado indistintamente causando así problemas al momento de caracterizar grupos sociales diferentes (Bonnier 1997:37). Hecha la aclaración, la única fuente disponible para establecer relaciones temporales, por ahora, es la cerámica cuya manifestación morfológica, tecnológica y estilística guarda mucha relación con las fases establecidas por Schreiber para el valle del Carhuarazo (Schreiber 1993:80).

Dadas esas características, hemos convenido la utilización de dicha clasificación hasta llevar a cabo nuestra propia secuencia temporal, para evitar la creación de nuevos términos que nos lleven a cometer graves confusiones; sin embargo hay que aclarar que tenemos muchos cuestionamientos sobre la secuencia temporal de Schreiber debido a que ésta fue elaborada con material de superficie recolectado durante su prospección arqueológica el año 1981.

Estilísticamente los fragmentos de cerámica recolectados son identificados como pertenecientes a las fases Marke, Toqsa y Jasapata. Estos materiales presentan características particulares, especialmente aquellos materiales pertenecientes al período Intermedio Tardío (Toqsa y Jasapata), hago énfasis en este punto pues la mayoría de investigaciones en la región de Ayacucho han caracterizado a la cerámica perteneciente a este período como parte de la tradición cultural Chanka (c.f. Lumbreras 1974; Gonzáles-Carré 1992; Valdez et al. 1990; Vivanco 2005).

En este caso, la cerámica perteneciente al asentamiento de Canichi difiere mayoritariamente de los tipos de cerámica Tanta Orqo, Qachisqo, Arqalla y Aya Orqo, tipos pertenecientes a la tradición cultural Chanka según la clasificación de Gonzáles-Carré (1992:57-59) y Lumbreras (1974:218-223), lo cual estaría advirtiendo una tradición alfarera distinta, cuyo rango de dispersión se encontraría al sur de Ayacucho en el valle del Carhuarazo desde finales del Horizonte Medio hasta el Horizonte Tardío dado que la alfarería de la fase Jasapata se extiende hasta dicho período compartiendo así, espacio y tiempo con la alfarería cuzqueña por lo que podría darse el caso que dentro de la fase Jasapata existan variantes de tradición alfarera local (Intermedio Tardío) que continúan produciéndose durante el Horizonte Tardío como también variantes que hayan sufrido la influencia del contacto con las tradiciones de manufactura cuzqueña (p.e. Inka local).

En síntesis, las evidencias recuperadas y registradas superficialmente identifican a Canichi como un asentamiento ocupado desde el período Intermedio Tardío hasta los primeros años de ocupación española en la región (Schreiber y Kintigh 1996:576), sin embargo es muy probable que este asentamiento tenga su origen en épocas más tempranas debido a la asociación directa con el sistema de caminos y las terrazas agrícolas, las cuales se edificaron durante la época 2 del Horizonte Medio (Schreiber 1987:270), a esto se suma que el material cerámico hallado en los rellenos de los muros se relacionan directamente con la fase Marke de Schreiber, la cual corresponde a las épocas 3 y 4 del Horizonte Medio según la secuencia estratigráfica estable- 
cida por dicha autora con los resultados de las excavaciones del sitio administrativo Wari de Jincamocco (Schreiber 1992). La corroboración de estas ideas referidas a los rangos temporales en Canichi depende únicamente de la realización de excavaciones sistemáticas en el mencionado asentamiento.

\section{LA OCUPACIÓN LOCAL DEL INTERMEDIO TARDÍO EN CANICHI}

Si bien se han mostrado posibles evidencias de una ininterrumpida ocupación desde finales del Horizonte Medio en este asentamiento, las evidencias más resaltantes y de mayor cantidad corresponden al período Intermedio Tardío, las cuales merecen ciertas aclaraciones y discusiones para poder entender mejor el panorama sociopolítico y económico previo a su anexión al Tawantinsuyu.

Las ideas en torno al grupo social establecido en Canichi durante el período Intermedio Tardío están relacionadas directamente con las evidencias materiales registradas al interior del asentamiento y a las características del entorno medio ambiental en el que se encontraba emplazado. La significativa cantidad de recintos de planta circular formando grupos o conjuntos arquitectónicos organizados alrededor de un espacio abierto o patio, de manera similar a los distintos asentamientos tardíos registrados en diferentes regiones de la sierra central (c.f. Bonnier 1997; DeMarrais 2001; Gonzáles-Carré 1992; Lavallée y Julien 1983; Perales 2004; Valdez et al. 1990; Valdez y Vivanco 1994), denotan claramente el carácter habitacional o residencial de Canichi. Además, las manos de moler, batanes, torteros, cerámica de carácter utilitario (cuencos, platos, ollas y cántaros), desechos de talla de material lítico y de cerámica halladas tanto en el interior como al exterior de las unidades arquitectónicas evidencian actividades domésticas relacionadas con la preparación de alimentos, elaboración de vasijas y artefactos líticos. Así, estos conjuntos habitacionales constituyeron la unidad básica de vivienda, la cual albergó posiblemente uno o más grupos familiares.
Evidencias relacionadas con aspectos de carácter defensivo son casi inexistentes a lo largo de todo el asentamiento. La inexistencia de muros perimétricos de gran magnitud, zanjas elaboradas en los bordes del asentamiento asociadas a estos muros, la fácil accesibilidad y visibilidad desde cualquier parte del valle no hacen otra cosa que poner en claro la mínima intención por parte de la población a establecerse en lugares estratégicos, defensivos y de difícil acceso. Estas características son contradictorias en muchos aspectos al compararlas con las evidencias registradas en la parte norte de Ayacucho, donde los asentamientos pertenecientes a estos períodos se encuentran en zonas muy difíciles de acceder (Bonavia 1972: 21-22; GonzálesCarré 1992: 41-42; Lumbreras 1974: 200-206; Valdez et al. 1990: 20-22; Vivanco 2005: 20-21). Para el valle del Carhuarazo, Schreiber plantea una situación similar con relación al patrón de asentamiento de los grupos sociales pertenecientes a este período, sin embargo el único sitio mencionado por la autora que cumple con estas características es Toqsa, el cual desempeñó una función de refugio defensivo ocupado temporalmente al cual recurrían los pobladores del valle ante la amenaza de grupos foráneos en expansión (Schreiber 1987: 274). Los asentamientos registrados durante nuestro trabajo de campo (incluido Canichi) contradicen estas aseveraciones, pues la mayoría de ellos no presentan elementos de carácter defensivo, lo cual advertiría un menor rango de belicosidad durante este período en esta región.

Otro aspecto a resaltar y que guarda relación con lo mencionado anteriormente es la asociación directa del asentamiento con un sistema de terrazas agrícolas de una considerable extensión y desarrollo tecnológico. Se plantea, específicamente para las cuencas del Pampas y Qaracha, un parcial distanciamiento de los valles fértiles que durante el Horizonte Medio fueron explotados intensivamente para la producción de maíz (Valdez et al. 1990: 18), cambiando de una economía de subsistencia basada en la agricultura a una economía pecuaria con ciertos enclaves 
en zonas bajas para la explotación de ciertos productos agrícolas (Gonzáles-Carré 1992: 95); sin embargo estas aseveraciones no son del todo claras en nuestra área de estudio, pues Canichi se encuentra ubicado en una región geográficamente apta para el desarrollo sostenible de la agricultura. Además, gracias a estudios interdisciplinarios de paleoecología, se sabe que a finales del Horizonte Medio (ca. 900 d.C.) se produjo un drástico cambio climático que afectó diversas regiones de los Andes Centrales, mermando las fuentes de agua tan importantes para el desarrollo de las actividades agrícolas durante el apogeo del Estado Wari (Thompson et al. 1975, citado en Santillana 2002: 557).

De acuerdo con Santillana (op.cit.: 558), es probable que los grupos del Intermedio Tardío en las distintas regiones de los Andes Centrales se desplazaran hacia zonas más elevadas en busca de nuevas fuentes de agua. En ese caso, probablemente los pobladores que se asentaron en Canichi pudieron ser grupos desplazados por este cambio climático a una zona de mayor elevación en busca de nuevas fuentes de agua y zonas fértiles, dedicándose exclusivamente a las actividades agrícolas y pastoriles, creando un sistema de relaciones complementarias entre ambas economías debido a la ausencia de una organización estatal reguladora (Duviols 1973: 184; Parsons et al. 1997: 318).

En resumen, dadas las evidencias registradas y las circunstancias en las que estas fueron recolectadas, podemos plantear hipotéticamente que Canichi fue un asentamiento de pobladores con una economía de subsistencia basada en la agricultura intensiva, interactuando con grupos de pastores de puna con los cuales intercambiaban productos de primera necesidad. A su vez, este asentamiento dentro de la cuenca baja del Negromayo habría sido el de mayor jerarquía, debido a la considerable importancia de su ubicación geográfica y por el rol que habría desempeñado como uno de los cuatro ayllus principales de la región antes de ser anexados al Tawantinsuyu (Monzón [1586]1965: 237).

\section{LA OCUPACIÓN INKA EN CANICHI}

Las evidencias relacionadas a una ocupación Inka en el asentamiento de Canichi son mínimas y hasta cierto punto sectorizadas. Estas evidencias se hallan en la parte más elevada del sector NEG-1A estando conformada por una estructura de planta rectangular asociada con alfarería cuzqueña de tipo imperial y provincial. Dicha estructura ya fue registrada por Schreiber, quien nos dice que la estructura se encuentra "...centrally located within the site is a rectangular building divided into two rooms by a long wall down the center. The building, of fieldstone construction (...) but it is clearly distinct from local constructions." (Schreiber 1993: 103) y cuya función fue la de residencia temporal del Inka o de un funcionario cuzqueño de segundo orden (op. cit.:104).

A esta estructura particular se suma otra que ubicamos muy cerca de esa área, se trata de un recinto de planta rectangular alargada el cual se encuentra aislado de las demás estructuras y que debido al mal estado de conservación no se pueden identificar con seguridad algún tipo de accesos u otro elemento arquitectónico complementario. Este tipo de estructura ha sido reportada en otros asentamientos con clara ocupación Inka y la han denominado Kallanka (Perales 2004: 166; Wernke 2006: 197-201). En ambos casos el uso del término podría llevarnos a ciertas confusiones pues la definición de $\mathrm{Ka}$ llanka guarda relación directa con un elemento arquitectónico típicamente Inka que está asociado a otros elementos arquitectónicos y espaciales (p.e. las Kanchas, el Ushnu y la Plaza) además de su ubicación sólo en centros de función administrativa (Farrington 1998; Hyslop 1990). De igual modo, las características que presenta la estructura registrada por Schreiber y esta última por nosotros, no guardan relación directa con las formas típicas de una edificación Inka (Kendall 1976: 63-77) salvo el tipo de planta, pero que igual no la hace necesariamente un edificio de clara inspiración cuzqueña.

En vista que las evidencias arquitectónicas no han ayudado a identificar una clara ocupación Inka, la cerámica hallada en el mencionado 
sector estaría dándonos una mínima evidencia para plantear todo lo contrario. Esto se debe principalmente a que la cerámica de factura cuzqueña hallada en Canichi es de tipo imperial y provincial lo cual haría más evidente la ocupación cuzqueña. Excavaciones sistemáticas en este sector podrían corroborar esta idea.

De manera contradictoria, al norte de Ayacucho, en las regiones del Pampas y Qaracha específicamente, el no tener afinada la secuencia alfarera local ha conllevado a este tipo de problemas, dado que las evidencias arquitectónicas y alfareras no son de carácter estatal sino más bien son las tradiciones locales que no han sido modificadas al ser anexadas al sistema administrativo Inka (Valdez 2002: 407-408; Valdez y Valdez 2002: 93).

Dadas las evidencias materiales discutidas anteriormente, es posible entonces que la ocupación Inka en Canichi haya sido de carácter administrativa con una autoridad cuzqueña residiendo en dicho asentamiento con el objetivo de supervisar y controlar a la población anexada, sin embargo aún quedan dudas sobre esta hipótesis que sólo excavaciones sistemáticas nos ayudaran a corroborar. Pero, si partimos de esta respuesta hipotética, cuál sería la razón para establecer un sector administrativo en Canichi, y qué ocurrió con la población local sujeta a este nuevo sistema de administración económica y política. De acuerdo con Schreiber, creemos que la región en conjunto, es decir, el valle del Carhuarazo y el valle del Negromayo estuvieron bajo el control administrativo de Apcara el cual, al igual que Queca, controlaron la región durante el gobierno estatal incaico, y estos a su vez estuvieron bajo el control de algún centro provincial de mayor envergadura, ya sea Hatun Soras o Hatun Lucanas (Schreiber 1987: 278, 1993: 113).

Es posible entonces que Canichi haya sido parte principal del sistema administrativo estatal, esto se debería principalmente a que el grupo poblacional que residía en este asentamiento estuvo dedicado al trabajo agrícola, medio económico de mucha importancia para el Estado Inka, sobre todo la dedicada a la producción de maíz $z^{4}$, planta de suma importancia no sólo para satisfacer la dieta de la clase dominante sino también para las distintas prácticas rituales dentro y fuera de la región. De esta manera, por intermedio de los grupos de elite incorporados a la esfera estatal incaica, no hubo la necesidad de imponer nuevas formas de centralización (D'Altroy 1987: 94; Perales 2004: 166; Schreiber 1987: 279; Wernke 2006: 201-202), conservando así su organización social de forma autónoma.

Entonces, puede que se haya dado el mismo fenómeno que en la región de Jauja, donde internamente los grupos familiares se mantuvieron como unidad económica básica de producción (DeMarrais 2001: 152), prueba de esto en Canichi sería la continuidad del manejo del espacio formal en la arquitectura de carácter habitacional, la cual no sufrió cambios drásticos en su organización ${ }^{5}$; no así en los espacios públicos, los cuales posiblemente se hayan trasladado hacia los recintos de mayor tamaño como los que se encuentran en la parte más levada del asentamiento, los cuales debían de tener un espacio más amplio para albergar una mayor producción de textiles y la preparación de alimentos, espe-

4 Las zonas agrícolas se ampliaron para garantizar una mayor producción de esta planta y también de otros productos. Las investigaciones de Meddens en el valle de Chicha-Soras y las de Proyecto Alto Mantaro (UMARP) sugieren que esta intensificación se debió principalmente a un aumento de las temperaturas, que a diferencia del período anterior, optimizó las condiciones para una mayor explotación de la tierra, construyendo un gran sistema de andenes el cual fue alimentado por el agua que discurría de los nevados por intermedio del deshielo de los glaciares (Branch et al. 2008:7; Seltzer y Hastorf 1990:411).

5 Excavaciones sistemáticas en diversos conjuntos habitacionales y el análisis de macro y micro restos serán de mucha utilidad para poder identificar patrones de consumo a nivel doméstico. Pues podría ocurrir, como lo plantea Hastorf para la región de Sausa un cambio en la organización de la producción agrícola durante la época Inka, el cual había modificando no sólo la producción de carácter estatal sino también la producción local a nivel familiar y el acceso a recursos, modificando así la dieta de los grupos locales (Hastorf 1990:268). 
cialmente de chicha para llevar a cabo festines auspiciados por el Inka en el marco de su principio de reciprocidad para el buen funcionamiento y crecimiento de las relaciones entre el Estado y las elites locales (Costin y Earle 1989: 706; Morris 1998: 304).

Los datos presentados y su comparación con el valle del Carhuarazo evidencian, al parecer, una continuidad en el sistema de organización social del grupo local anexado en ambas regiones, en el cual Canichi siguió manteniendo la jerarquía que había ostentado desde el período Intermedio Tardío, eso se debe principalmente a que en otros asentamientos registrados a lo largo de la cuenca no se han hallado evidencias clara de ocupación Inka, manteniendo las tradiciones locales de manera continua; en cambio en Canichi se observa una mínima pero marcada ocupación estatal. Su emplazamiento en la ecozona de producción de maíz habría sido también tomado en cuenta por el sistema administrativo cuzqueño siendo las labores agrícolas el modo de tributación al estado, de este modo se estaría contradiciendo el dato etnohistórico, pues por medio de éste se presumía que los grupos poblacionales en la región de Lucanas sólo tributaban cargadores y yanaconas ${ }^{6}$.

Para finalizar, de acuerdo con Schreiber, los grupos poblacionales locales tributaban con productos, especialmente maíz, los cuales fueron llevados a los centros de almacenamiento ubicados en la cercanía de los centros de Apcara y Queca siendo utilizados solamente para proveer tanto a la población local como al tampu ubicado cerca del camino principal y también para las obras comunales en favor del estado, debido a las pequeñas dimensiones que las estructuras de almacenamiento presentaban en comparación con los sistemas de almacenamiento estatales de Huánuco Pampa, Pumpu, Xauxa, Vilcashuamán, entre otros (Schreiber 1987:278). En este aspecto pudo Canichi ser partícipe de este sistema, tributando no sólo mano de obra local sino también productos agrícolas, tanto a estos centros secundarios coomo al centro administrativo principal, ya sea Hatun Lucanas o Hatun Soras.

\section{COMENTARIOS FINALES}

Es necesario recalcar que las ideas planteadas sobre el rol que pudo haber cumplido Canichi durante los últimos períodos de ocupación prehispánica se basan principalmente en datos de superficie y en explicaciones planteadas para otras regiones de la sierra central, sin embargo creemos que estas ideas pueden ser el inicio de una profusa investigación en una zona de relevante importancia para el entendimiento de los grupos poblacionales post-Wari, explicando el rol que pudieron haber tenido antes y durante de ser anexados al Tawantinsuyu.

Las evidencias presentadas sobre este asentamiento plantean nuevas explicaciones sobre el desarrollo de la cuenca del Negromayo durante estos períodos, pues como habíamos planteado al inicio de este reporte, partíamos de una hipótesis a priori basada principalmente en explicaciones generalizadas para otras regiones de los Andes Centrales. De esta manera, hemos observado que existen variabilidades en muchos aspectos en torno a las características de este asentamiento tanto para el período Intermedio Tardío como para el Horizonte Tardío.

Definitivamente quedan muchos trabajos por realizar a lo largo de la cuenca para poder explicar y comprender a cabalidad la situación de esta región durante dos períodos que han sido caracterizados a partir de datos etnohistóricos. Entender el proceso de conquista y consolidación de una región por los Inkas, parte esencialmente de la comprensión de la situación previa a la conquista, del desarrollo de los grupos locales pre-existentes en la región y de las necesidades que el aparato estatal demandó. En este caso, al ser una zona propicia para la actividad agrícola por lo fértil de los pisos ecológicos gracias

6 “... y los indios de este repartimiento (...) se ocupaban en traer al Inga y llevarle por toda esta tierra donde él quería ir, en unas andas (...) y ni mas ni menos le daban yanaconas [al Inka], que son criados de servicio; y ansí dicen que no daban otro tributo." (Monzón [1586] 1965:241). 
a encontrarse en zonas donde el recurso hídrico fue aprovechado de manera eficaz, la cuenca del Negromayo no dudo en ser una región de mucho beneficio para el Estado Inka.

En aspectos relacionados a la organización política, para la investigación arqueológica será difícil caracterizar un sistema de organización local antes de la conquista cuzqueña. Se ha discutido mucho el tema del origen y la organización de la confederación Chanka en muchas investigaciones, las cuales han condicionado y generalizado su extensión territorial a toda la región ayacuchana, salvo algunas excepciones. Es probable entonces que haya existido un grupo social diferente en la región, dada las evidencias arqueológicas registradas, sin embargo, aún no estamos en condiciones para asegurar y caracterizar a dicho grupo en particular.

\section{Agradecimientos}

El presente artículo no hubiese podido ser realizado sin la colaboración de algunas personas amigas que no dudaron en brindar un poco de su acortado tiempo de manera desinteresada. Quisiera agradecer en primer lugar al Mg. Manuel Aguirre-Morales por todo el apoyo y asesoramiento brindado hasta el momento, sus críticas y comentarios han contribuido enormemente al desarrollo de nuestra investigación, muchas gracias por confiar en nosotros. Quisiera agradecer también al equipo de investigación que durante tres años consecutivos han sido partícipes de los trabajos de campo. A Sonia Berrocal, Robert Coletti, Luis Escobedo, Christian Altamirano, Juan Neira y especialmente a Luis Flores (+), quien ya no está con nosotros físicamente pero quien de todas maneras estará acompañándonos en cada momento de nuestras futuras investigaciones, este trabajo va dedicado a él. A la Srta. Fátima Tito y a la familia Berrocal Huamaní por todo el apoyo brindado durante nuestra estadía en Andamarca, su logística es loable. Al Dr. Terence D'Altroy y a la Dra. Christine Hastorf por el poyo brindado al facilitarnos algunas de sus publicaciones de manera diligente y sin ningún contratiempo, no existen palabras para agrade- cer la generosidad. A Mónica Macha y Gonzalo Zavala por el apoyo en la edición final del presente artículo. Finalmente quiero dar un agradecimiento especial a mis padres por todo el apoyo emocional y material brindado desde mis inicios en la arqueología. A todos ellos, muchas gracias. Asumo la responsabilidad total de las ideas vertidas en este artículo.

\section{BiBliografía}

\section{ASOCIACIÓN LAGESA - CFGS}

1996 Geología de los cuadrángulos de Huancapi, Chincheros, Querobamba y Chaviña. Hojas (28-ñ), (28-o), (29-o) y (30-o). Lima: Instituto Geológico, Minero y Metalúrgico.

Bonavia, Duccio

1972 "Reconocimiento arqueológico en el área del Mantaro". Arqueológicas 14:11-40.

Bonnier, Elizabeth

1997 "Morfología del espacio aldeano y su expresión cultural en los Andes Centrales". En: Elizabeth Bonnier y Henning Bischof, eds. Archaeologica Peruana 2. Prehispanic architecture and civilization in the Andes, p.29-41. Mannheim: Sociedad Arqueológica peruano-alemana - Reiss Museum.

Branch, Nicholas, Rob Kemp, Barbara Silva, Frank Meddens, Alan Williams, Ann Kendall y Cirilo Vivanco

2007 "Testing the sustainability and sensitivity to climatic change of terrace agricultural systems in the Peruvian Andes: a pilot study". Journal of Archaeological Science 34(1):1-9.

Burger, Richard

2006 "Interacción interregional entre los Andes Centrales y los Andes Centro Sur: el caso de la circulación de obsidiana”. En: Heather Lechtman, ed. Esferas de interacción prehistóricas y fronteras nacionales modernas: los Andes sur centrales, p.423-447. Lima: Instituto de Estudios Peruanos - Ins- 
titute of Andean Research.

Burger, Richard, Katharina Schreiber, Michael Glascock y José Ccencho

1998 "The Jampatilla obsidian source: identifying the geological source of Pampas type obsidian artifacts from Southern Peru". Andean Past 5:225. 239.

Cámara, Jorge

2009 [Ms.] Patrones de asentamiento durante los períodos Intermedio Tardio y Horizonte Tardío en la cuenca baja del río Negromayo, Lucanas - Ayacucho. Informe presentado al curso de Prácticas Pre-profesionales 2. Lima: Universidad Nacional Mayor de San Marcos.

Costin, Cathy y Timothy Earle

1989 "Status distinction and legitimation of power as reflected in changing patterns of consumption in Late Prehispanic Peru". American Antiquity 54(4):691-714.

D'altroy, Terence

1987 "Transitions in power: centralization of Wanka political organization under Inka rule". Ethnohistory 34(1):78102.

D’altroy, Terence, Ana María Lorandi y Verónica Williams

1994 "Producción y uso de cerámica en la economía política Inka”. En: Izumi Shimada, ed. Tecnología y organización de la producción de cerámica prehispánica en los Andes, p.443-476. Lima: Pontificia Universidad Católica del Perú.

DeMarrais, Elizabeth

2001 "The architecture and organization of Xauxa settlements". En: Terence D'altroy y Christine Hastorf, eds. Empire and Domestic Economy, p.115156. New York: Kluwer Academic - Plenum Publishers.

Duviols, Pierre

1973 "Huari y Llacuaz: agricultores y pastores. Un dualismo prehispánico de oposición y complementariedad". Revista del Museo Nacional 39:153-191.

Farrington, Ian

1998 "The concept of Cusco". Tawantinsuyu 5:53-59.

Gonzáles-Carré, Enrique

1992 Los Señoríos Chankas. Lima: Instituto Andino de Estudios Arqueológicos - Universidad de San Cristóbal de Huamanga.

Hastorf, Christine

1990 "The effect of the Inka State on Sausa agricultural production and crop consumption". American Antiquity $55(2): 262-290$.

Hyslop, John

1990 Inka Settlement Planning. Austin: University of Texas Press.

Kendall, Ann

1976 "Descripción e inventario de las formas arquitectónicas Inca". Revista del Museo Nacional 42:13-96.

Lavalleé, Danièle y Michèle Julien

1983 Asto: curacazgo prehispánico de los Andes Centrales. Lima: Instituto de Estudios Peruanos.

Lumbreras, Luis

1974 “Chankas y Pocras". En: Las Fundaciones de Huamanga. Hacia una Prehistoria de Ayacucho. Lima: Club de Huamanga.

Monzón, Luis de, y otros

1965 [1586] "Descripción de la tierra del repartimiento de los Rucanas Antamarcas de la Corona Real, jurisdicción de la ciudad de Guamanga". En: Marcos Jiménez de la Espada, ed. Relaciones Geográficas de Indias, Tomo I, p.237-248 Madrid: Biblioteca de autores españoles.

Morris, Craig

1998 "Inka strategies of incorporation and governance". En: Gary Feinman y Joyce Marcus, eds. Archaic States, p.293-309. Santa Fe, New Mexico: School of American Research. 
Parsons, Jeffrey, Charles Hastings y Ramiro Matos

1997 "Rebuilding the State in Highland Peru: Herder-cultivator interaction during the Late Intermediate Period in the Tarama-Chinchaycocha region". Latin American Antiquity 8(4):317-341.

Perales, Manuel

2004 "La ocupación Inka en el valle de Cunas (Junín, Perú): una aproximación desde el sitio arqueológico de Arhuaturo". Arqueología y Sociedad 15:155172.

Santillana, Julián Idilio

2002 "Chancas e incas: un nuevo examen". En: Javier Flores-Espinoza y Rafael Varón, eds. El hombre y los andes: homenaje a Franklin Pease, Tomo II, p.553-566. Lima: Pontificia Universidad Católica del Perú - Instituto Francés de Estudios Andinos.

Schreiber, Katharina

1987 "Conquest and consolidation: a comparison of the Wari and Inka occupations of a Highland Peruvian Valley". American Antiquity 52(2):266-284.

1991 "The association between roads and politics: evidence for Wari roads in Peru". En: Charles Trombold, ed. Ancient Road Networks and Settlement Hierarchies in the New World, p.243. 252. Cambridge: Cambridge University Press.

1992 "Wari Imperialism in Middle Horizon Peru”. Anthropological Papers 87. Michigan: University of Michigan Press.

1993 "The Inca occupation of the Province of Andamarca Lucanas, Peru". En: Michael Malpass, ed. Provincial Inca: Archaeological and Ethnohistorical Assessment of the Impact of the Inca State, p.78-116. Iowa: University of Iowa Press.

Schreiber, Katharina y Keith Kintigh

1996 "A test of the relationship between site size and population". American Antiquity 61(3):573-579.
Seltzer, Geoffrey y Christine Hastorf

1990 "Climatic change and its effect on prehistoric agriculture in the Central Peruvian Andes". Journal of Field Archaeology 17(4):394-414.

Tosi, Joseph

1960 Zonas de vida natural en el Perú. Lima: Instituto Interamericano de Ciencias Agrícolas de la OEA.

Valdez, Lidio

2002 "Y la tradición continua: la alfarería de la época Inka en el valle de Ayacucho, Perú". Boletín de Arqueología PUCP 6:395-410.

Valdez, Lidio y Ernesto Valdez

2002 "El valle de Ayacucho y el Tawantinsuyo". Arqueología y Sociedad 14:7798.

Valdez, Lidio, Cirilo Vivanco y César Chávez

1990 "Asentamientos Chanka en la cuenca del Pampas Qaracha (Ayacucho)". Gaceta Arqueológica Andina 5(17):1726.

Valdez, Lidio y Cirilo Vivanco

1994 "Arqueología de la cuenca del Qaracha, Ayacucho, Perú". Latin American Antiquity 5(2):144-157.

Vivanco, Cirilo

2005 "El tiempo de los purun runas o Chankas en la cuenca del Qaracha, Ayacucho (Perú)”. En: Hiroyasu Tomoeda y Luis Millones, comps. Pasiones y desencuentros en la cultura peruana, p.13-29. Lima: Fondo Editorial del Congreso de la República.

Weberbauer, Augusto

1945 El Mundo Vegetal de los Andes Peruanos. Lima: Ministerio de Agricultura.

Wernke, Steven

2006 "The politics of community and Inka statecraft in the Colca Valley, Peru". Latin American Antiquity 17(2):177208. 